\title{
Can Continuing Legal Education Pass the Test? Empirical Lessons From the Medical World.
}

\author{
Rima Sirota \\ rs367@georgetown.edu
}

This paper can be downloaded free of charge from:

https://scholarship.law.georgetown.edu/facpub/2386

https://ssrn.com/abstract=3857997

Notre Dame Journal of Law, Ethics \& Public Policy, Vol. 36, Pp. 1-38.

This open-access article is brought to you by the Georgetown Law Library. Posted with permission of the author. Follow this and additional works at: https://scholarship.law.georgetown.edu/facpub

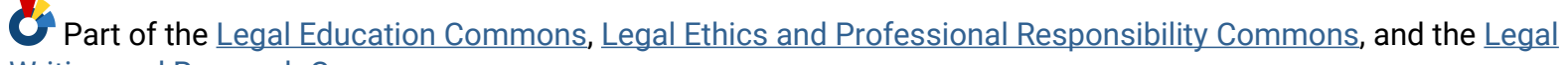
Writing and Research Commons 


\title{
ARTICLES
}

\section{CAN CONTINUING LEGAL EDUCATION PASS THE TEST? EMPIRICAL LESSONS FROM THE MEDICAL WORLD}

\author{
RIMA SIROTA*
}

INTRODUCTION

Respect for the legal profession was at a low ebb in the early 1970s due, in part, to lawyers' involvement in the Watergate scandal. ${ }^{1}$ Lawyers working on President Richard Nixon's reelection campaign, including former Attorney General John Mitchell, were among those who planned the burglary of the offices of the Democratic National Committee, and a raft of other government and private lawyers helped to cover up the crime. ${ }^{2}$ Both the judiciary and the public at large came to doubt whether lawyers as a group could be trusted to meet the profession's ethical obligations of competence and integrity. ${ }^{3}$

In response, national and state bar associations seized upon continuing legal education ("CLE") as a remedy. CLE, it was said, would keep lawyers abreast of important developments in the law and would reinforce lawyers' understanding of their ethical obligations. ${ }^{4}$ Moreover, mandating CLE would publicly demonstrate the profession's commitment to these goals. ${ }^{5}$ In 1975 ,

* Professor of Law, Legal Practice, Georgetown University Law Center. Many thanks to Erin Carroll, Kirsten Davis, Eun Hee Han, and Leah Rosenstiel for their feedback on drafts of this paper. I also greatly appreciate the research assistance provided by Emma Holland, Matthew Nussbaum, Elena Wang, and the Georgetown University Law Library.

1. See, e.g., Mark Curriden, The Lawyers of Watergate: How a "Third-Rate Burglary" Provoked New Standards for Lawyer Ethics, 98 A.B.A. J. 36, 36, 38 (2012).

2. See, e.g., id. at 38 (noting "the involvement of more than 20 of the most powerful lawyers in the United States"); Arnold Rochvarg, Enron, Watergate and the Regulation of the Legal Profession, 43 WASHBURN L.J. 61, 61-66 (2003).

3. See, e.g., Rocio T. Aliaga, Framing the Debate on Mandatory Continuing Legal Education (MCLE): The District of Columbia Bar's Consideration of MCLE, 8 GEO. J. LEGAL ETHICS 1145, 1150 (1995) ("Criticism of the legal profession was swelling in the early 1970s, as was a fear that the great number of lawyers entering the profession would lessen the quality of the bar."); Deborah L. Rhode \& Lucy Buford Ricca, Revisiting MCLE: Is Compulsory Passive Learning Building Better Lawyers?, 22 PRO. LAW. 2, 3 (2014) (discussing judicial dissatisfaction with lawyer performance in the early 1970s).

4. See, e.g., Curriden, supra note 1, at 42; Paul A. Wolkin, A Better Way to Keep Lawyers Competent, 61 A.B.A. J. 574 (1975).

5. See, e.g., ABA COMm. On CONTINUING Legal Educ., RePOrT On MOdel Rule For MiNIMUM CONTINUING LEGAL $\quad$ EDUCATION 3 (2017), https://www.americanbar.org/content/dam/aba/directories/policy/2017_hod_midyear_106.pdf [https://perma.cc/8Q7X-Z3ZL] (report begins on page 17 of the .pdf file) (identifying the profession's desire to "counteract negative publicity caused by the involvement of lawyers in the 
Minnesota and Iowa became the first American jurisdictions to require CLE. ${ }^{6}$ All but five jurisdictions have since followed suit. ${ }^{7}$

CLE, however, has yet to make any demonstrable progress toward these goals. Although the competence, ethics, and public relations justifications remain in heavy rotation among CLE regulators, ${ }^{8}$ no evidence-based reason has emerged to support the conclusion that CLE bears any relationship - much less a causal one - to better lawyering. ${ }^{9}$ Indeed, as demonstrated in Part I of this Article, CLE, an enormously expensive undertaking, has been subject to virtually no empirical study since its inception and remains mired in a pedagogical model that has been largely discredited by adult learning experts. As such, the mandatory CLE system in its current state is indefensible.

The legal profession can learn from the medical profession's approach to continuing learning. As demonstrated in Part II, medical empiricists have studied CME systems and programs from hundreds of angles. As a result, CME - in stark contrast to CLE - has evolved toward more interactive and purposeful programs in accordance with adult learning principles, demonstrably impacting CME efficacy.

Part III suggests a particular focus for legal empiricists ready to tackle the unexplored terrain of CLE efficacy: assessing CLE's potential to teach clientcentered communication skills. Medical and legal empiricists have demonstrated, respectively, that patient- and client-centered communication

Nixon Watergate scandal" as an impetus for the advent of mandatory CLE); Rhode \& Ricca, supra note 3, at 4, 7 (discussing CLE's "public relations" function).

6. David D. Schein, Mandatory Continuing Legal Education: Productive or Just PR?, 33 GEO. J. LEGAL ETHICS 301, 322-38 (2020) (providing the year each jurisdiction adopted mandatory CLE); see also ABA COMM. ON CONTINUING LEGAL EdUC., supra note 5, at 3; Jack. W. Lawson, Mandatory Continuing Legal Education and the Indiana Practicing Attorney, 40 VAL. U.L. REV. 401, 403 (2006)

7. Mandatory CLE, AM. BAR ASS'N, https://www.americanbar.org/events-cle/mcle/ (last visited Aug. 1, 2021) (clicking on "MCLE Rules By Jurisdiction" leads to a brief description of the CLE system in each jurisdiction). Maryland, Michigan, and South Dakota have no CLE requirements; the District of Columbia and Massachusetts require newly-admitted lawyers to complete a one-day jurisdiction-specific CLE course but have no additional CLE requirements. Id. See also, Schein, supra note 6, at 322-38 (providing a summary of each jurisdiction's CLE requirements).

8. For example, in Connecticut, which in 2017 became the most recent jurisdiction to require CLE, the purpose of the requirement is described as ensuring that lawyers "keep current with constantly evolving substantive and procedural law" and that they "maintain the requisite knowledge and skill necessary to practice in Connecticut effectively and fulfill their professional responsibilities." Minimum Continuing Legal Education: Frequently Asked Questions, ConN. JUD. BRANCH, https://jud.ct.gov/mcle/MCLE_FAQs.htm [https://perma.cc/RW6T-KAX3] (last visited Aug. 1, 2021); see also Rhode \& Ricca, supra note 3, at 7 (identifying "enhance[d] competence" and "enhance[d] public trust" as justifications put forth by mandatory CLE supporters); Aliaga, supra note 3, at 1162-63 ("Advocates argued [mandatory] CLE increases attorney competence, awareness of new issues in the law, [and] public confidence.").

9. Rima Sirota, Making CLE Voluntary and Pro Bono Mandatory: A Law Faculty Test Case, 78 LA. L. REV. 547, 553-60 (2018). 
styles can reap real-world benefits in the form of better practice and better medical and legal outcomes. The medical field, however, has gone a step further to also study how this essential skill can effectively be taught to practitioners through CME. Do the many CLE courses on client communication skills bear similar results? Could they do so with better course design? Answering these questions would be a significant first step toward understanding whether and how CLE might actually begin to accomplish its goals.

The imperative to study and improve CLE is plain, but, as addressed in Part IV, the profession may push back in subtle ways that incentivize researchers to produce evidence favorable to the current mandatory system or, at least, favorable to superficial fixes. Law journals continue to practice "publication bias," which favors positive results. Moreover, support from law schools, bar associations, and trade groups will be essential to CLE scholars, but each of these sectors has a vested interest in maintaining the mandatory CLE status quo. Whether this conflict of interest will influence critical inquiry into CLE remains to be seen.

One final note. Throughout this Article, references to "empirical" study are intended in the broadest sense: research based on data. ${ }^{10}$ A stricter definition — say, research using statistical techniques and analyses ${ }^{11}$ —may be appropriate down the road. At this point, however, simply recognizing and acting on the need for quantifiable measures of CLE efficacy would be an enormous step in the right direction.

\section{CONTINUING LEGAL EDUCATION (CLE)}

No national or state bar association or other CLE-related organization collects cost figures for CLE and makes them public. Extrapolating from the scant data available, one recent observer estimated that the average annual cost of mandatory CLE totals approximately $\$ 5,250$ per lawyer; this figure includes an estimated $\$ 100$ per credit hour for tuition plus the time spent taking courses, traveling to and from courses, and filing compliance documents with the lawyer's bar association. ${ }^{12}$ Using a much lower tuition estimate of $\$ 30$ per credit hour to account for the availability of free and lower-cost options, another recent paper estimated that 950,000 lawyers spent $\$ 345$ million on tuition for 11.5 million mandatory CLE hours in 2017. ${ }^{13}$

Both authors considered their estimates to be conservative. ${ }^{14}$ Even these low-end estimates, however, provide a sense of the enormity of the burden that

10. See Shari Seidman Diamond, Empirical Legal Scholarship: Observations on Moving Forward, 113 Nw. U. L. REV. 1229, 1232 (2019).

11. See id.

12. See Schein, supra note 6, at 304 .

13. Sirota, supra note 9, at 556-57 \& n.39. Unlike Schein's estimate, this accounting did not include time spent on travel or administrative paperwork. See id.; see also Rhode \& Ricca, supra note 3 , at 7 n.55 (summarizing earlier cost estimates).

14. See Schein, supra note 6, at 304; Sirota, supra note 9, at 556-57 \& 557 n.39. 
CLE has become - a burden disproportionately borne by new lawyers, public interest lawyers, solo practitioners, and lawyers of color. ${ }^{15}$ Given the magnitude of the undertaking, one might expect that the profession would have structured mandatory CLE in a manner that maximizes impact on practice and prioritizes testing the system through rigorous empirical study. The profession has failed on both accounts.

\section{A. CLE Structure}

Mandatory CLE proponents, including the American Bar Association, insist that the system helps keep lawyers up-to-date and otherwise fit to practice, thereby protecting the lay public from incompetent representation. ${ }^{16}$ Given the enormous investment of time and money required, the mandatory system could not otherwise be justified. ${ }^{17}$ However, the structure of the current systemrequiring a set number of CLE hours on any legal topic, regardless of relevance, and expecting little, if any, active engagement — belies proponents' assertions.

The mandatory CLE system is oriented toward attendance, not learning. Requirements vary from one jurisdiction to another, but, on average, lawyers in mandatory CLE jurisdictions are required to certify completion of 12.2 hours per year. ${ }^{18}$ Lawyers are subject to disciplinary penalties for failing to meet the required number of CLE hours. ${ }^{19}$ However, no state government or bar

15. See Richard Dietz, Continuing Legal Education Needs a Rework, N.C. STATE BAR J., Summer 2021, at 10, 11 (describing the disproportionate burden on lawyers of color); Carolyn Elefant, Why Can't CLE Deliver Real Value to Solos By Teaching Real Skills?, ABOvE THE LAW (Aug. 30, 2016, 6:02 PM), http://abovethelaw.com/2016/08/why-cant-cle-deliver-real-value-tosolos-by-teaching-real-skills/?rf=1 [https://perma.cc/ZHP2-2APX] (describing the disproportionate burden on solo practitioners); Schein, supra note 6, at 305-06 (describing the disproportionate burden on new lawyers); Marta-Ann Schnabel, A Long History of Service Gets Renewed Energy: Louisiana's Access to Justice Commission is a Collaboration of the Supreme Court, the LSBA and the LBF, 64 LA. BAR J. 260, 261-62 (2017) (describing the disproportionate burden on public interest lawyers).

16. See, e.g., Am. BAR Ass'N, Model RUle for Minimum Continuing Legal EDUCATION 1 (2017), https://www.americanbar.org/content/dam/aba/directories/policy/2017_hod_midyear_106.pdf [https://perma.cc/8Q7X-Z3ZL].

17. E.g., Victor J. Rubino, MCLE: The Downside, 38 CLE J. \& REG. 14, 14-15 (1992); Sirota, supra note 9 , at 550-51.

18. Calculations on file with the author. At the low end, Alaska and Hawaii require only three hours per year. See Schein, supra note 6, at 322, 325. At the high end, fourteen jurisdictions require an average of fifteen hours per year, though some spread the requirement over two or three years (for example, requiring completion of forty-five hours over a three-year period). Id. at 322 38. The 12.2-hour calculation does not take into account some jurisdictions' temporary relaxation of requirements during the COVID-19 pandemic. See Sarah Mills, All the States that are Changing their MCLE Rules due to the Coronavirus Pandemic, LAwLINE BLOG (Jan. 12, 2021), https://blog.lawline.com/all-of-the-states-that-are-waiving-live-cle-requirements-due-to-thecoronavirus-pandemic [https://perma.cc/5HCV-TADC].

19. See, e.g., Mike Frisch, CLE Suspension Unauthorized Practice Draws Proposed 60-Day Suspension, LEGAL PRO. BLOG (Jan. 3, 2020), 
association has any system in place to assess whether attendees have actually learned anything from their CLE hours, much less whether they have retained or effectively put that knowledge to use.

There is little reason to expect that they have. For example, lawyers can fulfill CLE requirements with courses on a dizzying array of subjects regardless of their relevance to the lawyer's current or intended future practice areas. Georgia CLE rules require trial lawyers to complete three hours of trial practice CLE every year, and Puerto Rico CLE rules require lawyers who are notaries to take six hours of notary CLE every two years, but no other jurisdiction's CLE rules require any lawyers to fulfill the required hours with practice-relevant courses. ${ }^{20}$ Some lawyers apply to specialty certification programs that require ongoing CLE relevant to the specialty area, but only a tiny percentage of American lawyers participate in such programs. ${ }^{21}$

Similarly, although almost all jurisdictions require that a small percentage of CLE hours be devoted to topics of particular local concern or, most commonly, "ethics" or "professional responsibility" courses, ${ }^{22}$ lawyers can

https://lawprofessors.typepad.com/legal_profession/2020/01/a-60-day-suspension-has-beenproposed-by-an-illinois-hearing-board-for-an-attorneys-practice-while-suspended-illinoisrequir.html\# [https://perma.cc/EH8N-86FT] (reporting a proposed sixty-day suspension for an Illinois lawyer practicing without having completed CLE requirements); Mike Frisch, This Time of Year: West Virginia Suspends 25 for CLE Lapses, Legal Pro. Blog (July 31, 2017), https://lawprofessors.typepad.com/legal_profession/2017/07/the-west-virginia-supreme-court-ofappeals-has-suspended-25-attorneys-for-cle-non-compliance.html [https://perma.cc/AY5U-3LJH] (reporting the suspension of twenty-five West Virginia lawyers for CLE non-compliance); Mike Frisch, Suspension Excessive for False CLE Submission, Legal Pro. Blog (Jan. 5, 2015), https://lawprofessors.typepad.com/legal_profession/2015/01/an-attorney-who-falsely-but-throughnegligence-rather-than-intent-to-deceive-certified-that-she-had-completed-cle-obligatio.html [https://perma.cc/6ZHB-EQFH] (reporting public reproval of a California lawyer who falsely certified completion of CLE requirements).

20. See Schein, supra note 6, at 322-38. Additionally, although not part of the CLE rules themselves, some state rules for appointment of counsel in capital cases require or encourage subject-specific CLE. See AM. BAR Ass'N, STATE STANDARDS FOR APPOINTMENT OF COUNSEL IN DEATH PENALTY CASES (Aug. 2018), https://www.americanbar.org/content/dam/aba/administrative/death_penalty_representation/state_ standards_memo_aug2018.pdf [https://perma.cc/546V-76NL].

21. For example, the California Board of Legal Specialization (CBLS) offers specialty certification in eleven areas of legal practice. About Certified Specialization, STATE BAR OF CAL., http://www.calbar.ca.gov/Attorneys/Legal-Specialization/About-Certified-Specialization (last visited Aug. 1, 2021) [https://perma.cc/3N2G-NPUV]. Certified specialists are required to complete thirty-six hours of specialty-specific CLE every three years. MCLE Requirements for Certified Specialists, STATE BAR OF CAL., http://www.calbar.ca.gov/Attorneys/Legal-Specialization/MCLERequirements-for-Certified-Specialists (last visited Aug. 1, 2021) [https://perma.cc/4VTG-3T2C]. However, only approximately three percent of California lawyers are certified by CBLS. California Board of Legal Specialization, LAW. LEGION, https://www.lawyerlegion.com/certifications/california (last visited Aug. 1, 2021) [https://perma.cc/3X25-BJ4P] ("Mission and History").

22. See Schein, supra note 6, at 322-38. Other common specialized requirements include substance abuse or mental health issues. See id. 
meet these requirements through courses that may or may not be relevant to their practice or to any particular ethics issues that they may be facing. ${ }^{23}$

A critic writing in 1992 referred to mandatory CLE as being based on the "THOA concept-Twelve Hours Of Anything." ${ }^{24}$ Thirty years later, little has changed.

One might think that mandatory CLE jurisdictions would not need to require lawyers to take practice-relevant CLE courses because lawyers, presumably, would choose to do so on their own. ${ }^{25}$ Time pressures, however, often dictate otherwise as the clock winds down on busy lawyers who must meet the CLE reporting deadline. ${ }^{26}$ The high cost of certain courses may also push lawyers to choose less relevant options. ${ }^{27}$ Indeed, a 1987 survey showed that lawyers in mandatory CLE jurisdictions took more courses outside their practice

23. By way of typical example, Alabama requires one hour per year of CLE "on the subject of ethics or professionalism." ALA. ST. BAR, Rules for Mandatory Continuing Education, R. 3 (2017), https://www.alabar.org/assets/2019/02/MCLE-RULE-BOOK-2017-updated-01-172017.pdf [https://perma.cc/F7WV-F8VG]; see also Jordan Furlong, The MCLE Question No One Wants to Ask, LAw21 BLOG (Apr. 4, 2013), https://www.law21.ca/2013/04/the-mcle-question-noone-wants-to-ask/ [https://perma.cc/HE74-APW8] (noting a disconnect between CLE offerings and the sources of lawyers' actual ethics problems).

24. See Rubino, supra note 17, at 16. This issue extends beyond the United States. See HoOK TANGAZA, INTERNATIONAL APPROACHES TO ONGOING COMPETENCE: A REPORT FOR THE LSB 17 18 (March 2021), https://legalservicesboard.org.uk/wp-content/uploads/2021/05/Internationalapproaches-to-Ongoing-Competence.pdf (critiquing the lack of connection between CLE requirements in the United Kingdom and lawyers' actual practices).

25. See, e.g., Gina Roers-Liemandt, No Such Thing as "One-Size-Fits-All" CLE, LAW PRAC. TODAY (Jan. 13, 2017), https://www.lawpracticetoday.org/article/no-thing-one-size-fits-cle/ [https://perma.cc/97Q5-E7BD] (extolling, in an ABA publication, the great flexibility afforded lawyers in fulling CLE requirements).

26. The internet abounds with options for lawyers who "need to fill up their CLE hours in one sitting or just want to get it over with.” Jenny Tsay, CLE Binge: 3 Last Minute Ways to Complete Your Hours, FindLAw Blogs (Jan. 16, 2014, 11:55 AM), https://blogs.findlaw.com/greedy_associates/2014/01/cle-binge-3-last-minute-ways-to-completeyour-hours.html [https://perma.cc/PYZ5-TX2L]; see also, e.g., Scott Stewart, Several Last-Minute CLE Opportunities Available, THE DAILY RECORD (Dec. 13, 2019, 12:45 am), https://omahadailyrecord.com/content/several-last-minute-cle-opportunitiesavailable [https://perma.cc/ZR4J-Y62V] (describing Nebraska CLE opportunities "through the final hours of 2019 in an effort to help procrastinating attorneys fulfill their obligations"); CLE Blast 2019: Last Minute CLE Your Way, Tenn. BAR ASS'N ClE Course Catalog, https://cle.tba.org/catalog/course/4965 [https://perma.cc/GD5P-9M4J] (describing "last minute" full-day courses offered just in time to meet the Tennessee CLE reporting deadline).

27. See, e.g., Sarah Diane McShea, Professional Obligations for Lawyers-Are You in Compliance?, N.Y. ST. BAR Ass'N J., May 2019, at 48, 50 (noting cost as a hurdle to completing CLE requirements); Claudine V. Pease-Wingenter, Halting the Profession's Female Brain Drain While Increasing the Provision of Legal Services to the Poor: A Proposal to Revamp and Expand Emeritus Attorney Programs, 37 OKLA. CITY U.L. REV. 433, 459 (2012) (noting most lawyers cannot fulfill all required hours through free or low-cost options). 
areas than lawyers in non-mandatory CLE jurisdictions, suggesting that the mandatory CLE model "skews lawyers" continuing education priorities." 28

Even if a lawyer makes relevant CLE choices, lecture-based courses with little opportunity for interactivity or practice are unlikely to deliver lessons that stick. ${ }^{29}$ Although theoretical approaches to adult learning differ, certain basic principles are broadly accepted. ${ }^{30}$ Courses for working professionals should "provide the kind of environment that experts find conducive to adult learning, which involves preparation, participation, evaluation, accountability, and opportunities to apply new information in a practice setting." 31 Yet, CLE courses "[a]lmost never" follow this model. ${ }^{32}$ Rather, the typical CLE course involves an expert speaker presenting material to a largely passive audience. ${ }^{33}$

Why have CLE courses remained so unengaging? Deborah Rhode and Lucy Ricca suggest several reasons. With a mandatory system, the impetus to improve the quality of course offerings is low-CLE providers may compete with one another, but they have an enormous captive audience. ${ }^{34}$ Moreover, the cost of developing quality programming has long been a stumbling block to improving the system. ${ }^{35}$ So too has been the cost to CLE regulators of rigorously evaluating CLE proposals and presenters. ${ }^{36}$ Finally, CLE supporters have been able to rely on the facile proposition that lawyers are bound to learn something by attending, as if learning anything at all justifies required attendance. ${ }^{37}$

Some CLE organizers and scholarly observers have acknowledged and acted on the need for change. For example, organizers of a Michigan CLE program for lawyers who serve as appointed counsel observed that "recent paradigm shifts in adult education demand more" than lecture-based courses, causing the organizers to incorporate features such as a multi-day appellate writing workshop and monthly virtual-case rounds. ${ }^{38}$ Another writer proposed pairing participants in an ethics CLE program; the first lawyer would reflect, in

28. Rubino, supra note 17 , at 17.

29. See, e.g., Rhode \& Ricca, supra note 3, at 8.

30. See, e.g., David C. M. Taylor \& Hossam Hamdy, Adult Learning Theories: Implications for Learning and Teaching in Medical Education, 35 MED. TCHR. e1561, e1562-63 (2013) (describing various adult learning theories and noting the significant overlap among them).

31. Rhode \& Ricca, supra note 3, at 8; see also Anita Bernstein, Minding the Gaps in Lawyers' Rules of Professional Conduct, 72 OKLA. L. REV. 125, 144-45 (2019); H. Lalla Shishkevish, Continuing Legal Education: The Future is Now, MiCH. BAR J., June 2017, at 36, 37.

32. Rhode \& Ricca, supra note 3 , at 8.

33. Id.; see also Barbara A. Bichelmeyer, Best Practices in Adult Education and ELearning: Leverage Points for Quality and E-Learning: Leverage Points for Quality and Impact of CLE, 40 VAL. U.L. REV. 509, 511-12 (2006).

34. See Rhode \& Ricca, supra note 3 , at 9 .

35. See id. at 5-6.

36. See id. at 6.

37. See id. at 7.

38. Bradley R. Hall \& Kathryn R. Swedlow, Ensuring Independence and Quality in a Managed Assigned Counsel System, MiCH. BAR J., Jan. 2019, at 26, 29. 
writing, on their experience with a particular rule of professional conduct, and the second lawyer would reflect, also in writing, on the first participant's submission. ${ }^{39}$ Yet another proposal would have teams of bar authorities, practitioners, CLE providers, and others identify concrete competencies necessary for specific practice areas, followed by a series of CLE learning activities focused on those skills. ${ }^{40}$

To what extent have such ideas been implemented and repeated? To what extent are lawyers choosing them? To what extent do such courses deliver on their promise to meaningfully impact an attendee's practice? As addressed in the following section, the literature offers virtually no evidence-based answers to these foundational questions.

\section{B. A Requirement with No Evidence of Efficacy}

Legal empirical study is a growing field; indeed, the increasing trend toward legal empirical work has itself been established empirically. ${ }^{41}$ The trend is powered by increases in data availability, the number of law professors trained in quantitative and qualitative research methods (including law professors with Ph.D. degrees), and demand by law reviews for empirically based research. ${ }^{42}$ Many legal fields and sub-fields have received empirical treatment, from family law to international economic law to procedural rule-

39. Bernstein, supra note 31 , at $145-47$.

40. Shishkevish, supra note 31, at 37; see also, e.g., Art Hinshaw \& Jess K. Alberts, Doing the Right Thing: An Empirical Study of Attorney Negotiation Ethics, 16 HARV. NEGOT. L. REV. 95, 158 (2011) (proposing an experiential learning program with feedback, followed by hypothetical examples); Randall T. Shepard, Elements of Modern Court Reform, 45 IND. L. REV. 897, 907 (2012) (describing an Indiana conference designed to help nonprofit CLE providers understand adult learners' educational needs); Wendy L. Werner, Holding an In-House Technology Seminar, LAW PRAC., March/Apr. 2017, at 64, 64-65 (describing how a law office could organize a CLE technology program that incorporates collaboration and other adult learning practices).

41. See Diamond, supra note 10, at 1230 ("Studies using a variety of methods and definitions of 'empirical research' all find that empirical scholarship reported in law reviews has grown and appears to be continuing to grow."); Michael Heise, An Empirical Analysis of Empirical Legal Scholarship Production, 1990-2009, 2011 U. ILL. L. REV. 1739, 1741-46 (2011) (documenting the increase in empirical legal scholarship beginning in the 1990s).

42. See, e.g., Christina L. Boyd, In Defense of Empirical Legal Studies, 63 BufF. L. REV. 363, 371-72 (2015); Diamond, supra note 10, at 1229-30; Heise, supra note 41, at 1746-49; Lynn M. LoPucki, Disciplinary Legal Empiricism, 76 MD. L. REV. 449, 454-55 (2017). 
making, to name just a few. ${ }^{43}$ The field has also trained its sights on law schools, with studies looking at various aspects of law school pedagogy and culture. ${ }^{44}$

CLE, however, has received almost no empirical attention. ${ }^{45}$ The few studies that have attempted to collect and analyze CLE-related data hint at the system's potential strengths, but mostly highlight its weaknesses. None of the studies provide any reason to believe that the current mandatory CLE system results in better lawyering than would be the case without CLE requirements. More than forty-five years after Minnesota and Iowa imposed the first CLE requirements, the continuing absence of data renders the system difficult to justify. ${ }^{46}$

Most CLE-related empirical work assesses lawyers' opinions about CLE generally. Barbara Bichelmeyer, for example, interviewed thirteen lawyers about their experiences with CLE. ${ }^{47}$ The responses were both positive (for example, knowledgeable presenters, helpful course materials, and networking opportunities) and negative (for example, variation in quality, lack of interactivity, and cost). ${ }^{48}$ Although the study's subjects practiced in both

43. See Robert G. Bone, The Empirical Turn in Procedural Rule Making: Comment on Walker (1), 23 J. LegAL STUD. 595 (1994); Clare Huntington, The Empirical Turn in Family Law, 118 Colum. L. Rev. 227 (2018); Beth A. Simmons \& Andrew B. Breidenbach, The Empirical Turn in International Economic Law, 20 MINN. J. INT'L L. 198 (2011). Perusing article titles in the Journal of Empirical Legal Studies provides a good sense of the enormous substantive breadth of the field. See JOURNAL OF EMPIRICAL LEGAL STUDIES, https://onlinelibrary.wiley.com/journal/17401461 (last visited Aug. 1, 2021).

44. See, e.g., Fiona Cownie, Legal Education and the Legal Academy, in THE OXFORD HANDBOOK OF EMPIRICAL LEgAl ReSEARCH 854, 855 (Peter Cane \& Herbert M. Kritzer eds. 2010); see also, e.g., Catherine Albiston et al., Making Public Interest Lawyers in a Time of Crisis: An Evidence-Based Approach (Oct. 15, 2020), 34 Geo. J. LEGAL ETHICS 223 (2021) (describing particular empirical study of how law schools can help law students build long-term public interest careers).

45. See, e.g., Holly B. Fisher, Exploring Programmatic Issues Which Affect Continuing Legal Education Practice in Kansas at 44 (2017) (Ed.D. dissertation, Kansas State University), https://krex.k-state.edu/dspace/handle/2097/35383 [https://perma.cc/88C8-KJL3]; Schein, supra note 6 , at 305 .

46. See, e.g., Aliaga, supra note 3, at 1156 ("Without hard data demonstrating that mandatory CLE is beneficial, the claim that increased competence results from participation in MCLE courses is nothing more than an unsubstantiated assertion."); Fisher, supra note 45, at 9 (noting the importance of undertaking empirical research given the significant investment required to conduct, attend, and administer CLE); Furlong, supra note 23 ("There isn't any causal link between [mandatory] CLE and law competence. We might as well get that out there."); Sirota, supra note 9 , at 557 ("To say that no data supports a correlation between mandatory CLE and competence is no exaggeration."); HOOK TANGAZA, supra note 24, at 15-16 (noting the absence of evidence in the United Stated and elsewhere establishing that CLE leads to improved competence).

47. Bichelmeyer, supra note 33 , at 510-12.

48. Id. at 511-12. 
mandatory and non-mandatory CLE states, Bichelmeyer did not explore any differences in that regard. ${ }^{49}$

Several researchers have explored aspects of CLE beyond participant lawyers' opinions about the system. For example, Holly Fisher surveyed Kansas CLE providers regarding that state's requirements and programs. ${ }^{50}$ Fisher found that the bulk of Kansas CLE offerings were traditional lecturesthe type of course widely acknowledged by experts to be ineffective as a mode of adult learning. ${ }^{51}$ Nonetheless, Fisher found some cause to be hopeful in that the CLE providers were enthusiastic about and making some strides toward improving their offerings by consulting with other stakeholders (attendees, employers, and regulators) and incorporating more interactive learning modes, such as discussion groups and mock trials. ${ }^{52}$

Kimberly Ann Thomas looked at the efficacy of online CLE programs, which CLE regulators have increasingly approved for credit. ${ }^{53}$ Thomas observed that adult learning researchers have, as a general matter, demonstrated an array of benefits from online courses, including the potential for "significant professional growth." 54 As regards CLE, however, Thomas's interviews with fifteen North Carolina lawyers suggested a negative experience with online

49. See id. at 510-11. Other survey studies include Barbara J. Daley, Learning and Professional Practice: A Study of Four Professions, 52 Adult EDUC. Q. 39, 39, 42, 45 (2001) (interviewing twenty lawyers who for the most part reported that they used CLE to help assess and solve clients' legal problems and to expand their practices into new areas); Marian Kathleen Fukuda, Elements of a Program Design for Continuing Legal Education for Los Angeles County Public Defenders (June 1980) (Ed.D. dissertation, University of Southern California) (ProQuest) (finding support among surveyed public defenders in Los Angeles for voluntary CLE programs offered in their offices); Evangelina Benavides Moore, The Attitudes and Behavioral Intentions of Texas Attorneys Toward Continuing Legal Education (Dec. 1986) (Ed.D. dissertation, Texas Woman's University) (ProQuest) (finding that surveyed Texas lawyers held overall positive views of CLE programs but also believed that CLE should be voluntary); TENN. COMM'N ON CONTINUING LEGAL EDUC., MANDATORY CLE SURVEY ANALYSIS (2006), https://www.cletn.com/images/Documents/Archives/2006/MandatoryCLESurveyAnalysis2006.pd f [https://perma.cc/V6ZL-9B7E] (providing a bare-bones "analysis" of the results of an online survey of Tennessee lawyers and concluding that they held "overwhelming[ly] positive" views of CLE).

50. Fisher, supra note 45.

51. Id. at 192-94.

52. Id.

53. Kimberly Ann Thomas, Attorneys' Experiences with Continuing Legal Education Delivered Online: A Holistic Single Case Study 13 (Nov. 2019) (Ed.D. dissertation, Liberty University), https://digitalcommons.liberty.edu/doctoral/2243/ (documenting increasing popularity of online continuing education courses in various professions, including law); see also Lucy Endel Bassli, The Legal Education Gap, LEGAL Bus. WORLD (Jan. 21, 2019), https://www.legalbusinessworld.com/post/2019/01/21/the-legal-education-gap

[https://perma.cc/49JX-HXHW] (noting the trend toward allowing credit for online CLE programs, including both synchronous and asynchronous delivery methods).

54. Thomas, supra note 53, at 40 . 
programs, with the lawyers reporting little engagement during the courses and, afterward, little impact on their practice. ${ }^{55}$

Finally, two studies analyzed data regarding complaints against lawyers and CLE requirements in the jurisdictions where they practice. ${ }^{56}$ This idea is intriguing, as fewer complaints might at least suggest a connection between mandatory CLE and improved lawyering. ${ }^{57}$ Neither study, however, found a significant relationship. ${ }^{58}$

The most recent of these studies, by David Schein, reviewed disciplinary actions in various jurisdictions in 2002, 2010, and 2015, finding no relationship between the level of a jurisdiction's CLE requirements and the number of lawyers disciplined by bar authorities. ${ }^{59}$ Indeed, Schein found that, on average, jurisdictions with no CLE requirements had lower rates of disciplinary complaints than jurisdictions where CLE is mandatory ${ }^{60}$ Schein also found that instituting mandatory CLE had no effect on lowering the rate of legal malpractice complaints in a jurisdiction. ${ }^{61}$

The other disciplinary data study was published by "CLEreg," a national trade group for administrators of mandatory CLE programs, ${ }^{62}$ and was conducted by Chris Ziegler and Justin Kuhn, authors whose credentials are not provided. ${ }^{63}$ Ziegler and Kuhn looked at the relationship between introducing mandatory CLE in a jurisdiction and (1) the number of disciplinary complaints filed in that jurisdiction, (2) the number of complaints found substantial enough to merit full investigation, and (3) the number of complaints for which discipline was ultimately imposed. ${ }^{64}$

55. Id. at 95-97.

56. See Schein, supra note 6; Chris Ziegler \& Justin Kuhn, Is MCLE a Good Thing? An Inquiry Into MCLE and Attorney Discipline, Continuing Legal EdUC. REguls. Ass'N, at 7 \& n.8, https://www.clereg.org/assets/pdf/Is_MCLE_A_Good_Thing.pdf.

[https://perma.cc/Q9BH-SVWZ]. Although the Ziegler and Kuhn paper is undated, references within the paper suggest that it was likely written in 2013.

57. See Sirota, supra note 9 , at $554 \&$ nn.27 \& 28 (collecting sources that have noted the absence of empirical findings in this regard).

58. A similar study was reported to have been undertaken in 2012 by the Indiana Commission for CLE. Shepard, supra note 40, at 907 . The author's efforts to locate reports on the progress or results of this study were unsuccessful, and an inquiry to the Indiana Commission went unanswered.

59. Schein, supra note 6 , at $312-15$.

60. Id. at 315 .

61. Id. at 315-18. Given the absence of a national index of disciplinary and malpractice claims by state and date, Schein's conclusions regarding disciplinary and malpractice complaints were based on what Schein described as "significant anecdotal evidence." Id. at 315.

62. About Us, CONTINUING LEGAL EDUC. REGULS. Ass'N, https://www.clereg.org/about (last visited Aug. 1, 2021), [https://perma.cc/KR3K-9LE4].

63. See Ziegler \& Kuhn, supra note 56, at 1 .

64. Id. at 10. The authors reviewed disciplinary rates in five states that implemented mandatory CLE between 2000 and 2010. Id. at 9-10. 
The study found no statistically significant reduction in the first and third categories. ${ }^{65}$ Nonetheless, these authors declared mandatory CLE to be "a good thing" because the introduction of mandatory CLE was correlated with fewer complaints in the second category. ${ }^{66}$ A complaint is not advanced to a full investigation unless a bar investigator determines that the complaint should be "summarily dismissed." 67 Essentially, then, the study's only statistically significant finding was a correlation between the introduction of mandatory CLE and fewer frivolous complaints. Ziegler and Kuhn determined that mandatory CLE was not only correlated with this reduction but actually caused it. ${ }^{68}$ It is difficult to understand the logic of this conclusion, much less how it justifies CLE being a "good thing." 69

As demonstrated by the foregoing discussion, little research has focused on CLE and the research that does exist provides no justification for a mandatory CLE system. Of course, there may be enormously effective CLE courses hidden within the vast array of offerings - courses that positively impact attending lawyers' understanding of the law, practice of law, and ability to improve the experience of their clients. Identifying such courses and how they achieve such benefits might begin to pave the way forward for a CLE system that demonstrably achieves more than mere attendance.

\section{CONTINUING MEDICAL EDUCATION (CME)}

Mandatory CLE proponents often argue that without a CLE requirement, the legal profession's reputation would suffer by comparison to other professions. ${ }^{70}$ Because "doctors and accountants, ... acupuncturists, barbers, cosmetologists, and real estate appraisers" are required to take continuing education courses, the bar "would jeopardize its own public standing if it failed to follow suit."71 This rationale has been particularly prominent in proposals to adopt or maintain mandatory CLE in various jurisdictions. For example, in supporting a CLE requirement in California, the state bar there argued, "It would be cavalier, if not shocking, were California lawyers excused from the obligation to continue to learn, while all those other California professionals ... are required to discharge it." 72

65. Id. at $1,10,13-14$

66. See id. at 13-14.

67. Id. at 10 .

68. See id. at 14

69. See Sirota, supra note 9, at 559-60 (critiquing the Ziegler \& Kuhn study).

70. See, e.g., Joseph Marino, Ask the Professor: Why Do We Need Continuing Legal Education?, ABOVE THE LAW (Jan. 8, 2015), https://abovethelaw.com/2015/01/ask-the-professorwhy-do-we-need-continuing-legal-education/ ("Most all other professions require [continuing education], and, as attorneys, we should not give the impression we are above keeping up with the law.").

71. Rhode \& Ricca, supra note 3, at 7 (describing but not endorsing the argument).

72. State BAR of CAL., MClE Evaluation COMMission RePORT 15 (2001); see also, e.g., CONn. BAR ASS'N, CONTINUING Legal Educ. COMM., A Proposal FOR Minimum 
This everybody-else-does-it argument has a certain "surface appeal.".73 Ultimately, however, it "misses the point[.] Before there were dermatologists, all doctors were bleeding patients with leeches. It doesn't matter if everybody is doing it. What matters: is it worth doing?"'74

The legal profession has yet to examine whether CLE is "worth doing," much less prove it, but other professions have turned an empirical spotlight on the efficacy of their own continuing education practices. ${ }^{75}$ Researchers have found, for example, that accountants who do not perceive mandatory continuing education as being effective are less likely to choose challenging courses or to pay full attention in class; ${ }^{76}$ that informal means of continuing education for social workers might have more impact on practice than formal, regulated continuing education; ${ }^{77}$ and that focused continuing education for math teachers could help address academic challenges faced by students for whom English is a second or third language. ${ }^{78}$

No continuing education field has received more empirical attention than medicine. ${ }^{79}$ Like CLE, continuing medical education is a massive undertaking - a $\$ 3$ billion industry in $2020 .{ }^{80}$ Unlike CLE, however, the CME

Continuing Legal Education IN COnNecticut $9-10 \quad$ (2006),
https://cdn.ymaws.com/www.newhavenbar.org/resource/resmgr/imported/CT_MCLE_WhitePape r2-06.pdf [https://perma.cc/VF8T-5HJK] (arguing that Connecticut lawyers should join the "diverse group of Connecticut professionals" - everyone from realtors to landscape architects to massage therapists - who are required to "remain up to date in their occupation"); Happy 30th Birthday to Mandatory CLE, LAws. MUTUAL (Sept. 17, 2018), https://www.lawyersmutualnc.com/blog/happy30th-birthday-to-mandatory-cle [https://perma.cc/C9S4-6Q3Q] (deriding lawyer opposition to mandatory CLE in North Carolina by comparison to "school teachers, doctors and accountants," among other professionals, who "have not been reluctant" to impose continuing education requirements on themselves); J. Thomas Lenga, Minimum Continuing Legal Education-Not Your Father's Oldsmobile, 9 LABOR \& EMP. LAWNOTES 1, 2 (1999) (arguing in favor of adopting mandatory CLE in Michigan: "[W]ould you consult with a doctor [who] had taken no course to update herself or himself on the latest diagnostic techniques? Would you trust your tax return to an accountant who relied solely on his or her college degree courses?").

73. Stuart M. Israel, On Mandatory CLE, Tongue Piercing and Other Related Subjects, 9 LABOR \& EMP. LAWNOTES 3, 3 (1999).

74. Id.

75. See, e.g., Fisher, supra note 45 , at 25-37 (reviewing empirical research on continuing professional education generally and in various specific professions).

76. Susan B. Wessels, Accountants' Perceptions of the Effectiveness of Mandatory Continuing Professional Education, 16 ACCT. Educ.: AN INT'L J. 365, 367 (2007).

77. C.A. Smith et al., Staying Current in a Changing Profession: Evaluating Perceived Change Resulting from Continuing Professional Education, 42 J. SOC. WORK EDUC. 465, 475 (2006).

78. Karen E.L. Ross, Professional Development for Practicing Mathematics Teachers: A Critical Connection to English Language Learner Students in Mainstream USA Classrooms, $17 \mathrm{~J}$. MATH TCHR. EDUC. 85, 97 (2014).

79. See, e.g., Fisher, supra note 45 , at 33.

80. See ACCREDITATION COUNCIL FOR CONTINUING MED. EduC., ACCME DATA REPORT: StEAdy Growth IN ACCREdited Continuing MedicAl Education - 2019 (2020), 
system has evolved in response to decades of scholarship that examines every facet of physicians' career-long learning. As such, CME scholarship provides a model for how legal empiricists might study and improve CLE.

\section{A. CME Structure}

From the beginning of the twentieth century, the American Medical Association urged local medical societies to offer weekly voluntary educational programs for their members. ${ }^{81}$ With a growing consensus that CME was "synonymous" with "good practice" - necessary to keep up with rapidly changing medical knowledge - the voluntary aspiration eventually became a mandatory obligation. ${ }^{82}$ In 1947, the American Academy of General Practice became the first specialty board to require CME for membership; in 1965, Oregon became the first state to require CME for licensure. ${ }^{83}$

As indicated by this history, CME requirements come from two sources: state-specific licensing requirements and specialty board certification requirements. ${ }^{84}$

First, every American physician must be licensed in the jurisdiction where they practice, and they must maintain that credential through an ongoing "maintenance of licensure" ("MOL") process. ${ }^{85}$ In almost every jurisdiction, the MOL process includes required CME, with the particulars of the requirement established by the jurisdiction's medical licensing board. ${ }^{86}$ With

https://www.accme.org/sites/default/files/2020-

07/872_2020\%2007\%2028_2019_Data_Report.pdf [https://perma.cc/W47T-F2DT]. Fifty-five percent of this figure comes from participant registration fees. Id. The figure does not include a cost estimate for the number of hours spent traveling to and from courses, attending courses, and submitting paperwork documenting attendance. See id.

81. Alejandro Aparicio et al., Supporting Physician Lifelong Learning Through Effective Continuing Medical Education and Professional Development, 102 J. MED. Regul. 7,7 (2016);

Phil R. Manning \& Lois DeBakey, Lifelong Medical Education: Past, Present, Future, in Continuing Medical Education: Looking Back, Planning Ahead 17-18 (Dennis K. Wentz ed., 2011)

82. Manning \& DeBakey, supra note 81, at 17; Jonathan L. Vandergrift et al., Do State Continuing Medical Education Requirements for Physicians Improve Clinical Knowledge?, 53 HEALTH SERVS. RSCH. 1682, 1683 (2018).

83. Manning \& DeBakey, supra note 81 , at 18 .

84. See generally Aparicio et al., supra note 81 (describing CME history, including the development of state and specialty board requirements).

85. David Price, Clarifying the Difference Between Medical Licensure and Board Certification, AM RoundS (Jan. 12, 2016), https://academicmedicineblog.org/clarifying-thedifference-between-medical-licensure-and-board-certification/ [https://perma.cc/KC7P-HTF9].

86. See Continuing Medical Education: Board-by-Board Overview, FED'N OF STATE MED. BDS. (last updated Dec. 7, 2021), http://www.fsmb.org/siteassets/advocacy/key-issues/continuingmedical-education-by-state.pdf [https://perma.cc/4CVM-G9BJ] [hereinafter $\quad$ FSMB Chart (compiling jurisdiction-by-jurisdiction CME requirements). 
just five exceptions, all American jurisdictions require an average of between fifteen and fifty CME credits per year. ${ }^{87}$

Like mandatory CLE hours, most MOL-required CME hours can be fulfilled with courses on virtually any topic. ${ }^{88}$ Only six jurisdictions require that any MOL CME credits be earned in the doctor's primary area of practice. ${ }^{89}$ Also like CLE, many jurisdictions mandate content-specific requirements on topics of particular local concern, such as opioid or other pain management issues, suicide detection, child abuse recognition, or sexual harassment prevention, but these requirements typically account for only a small percentage of the required hours. ${ }^{90}$

Unlike jurisdiction-based MOL programs, specialty board CME requirements focus on member physicians' specific areas of practice. ${ }^{91} \mathrm{CME}$ is required of all specialty certified physicians as part of a four-part ongoing "maintenance of certification" ("MOC") program. ${ }^{92}$ American physicians do

87. See id. Vermont and Wisconsin require an average of fifteen hours per year; nine jurisdictions require an average of fifty hours per year; the other jurisdictions require an average of between twenty and thirty hours per year. Id. Most jurisdictions spread the requirement over two or three years (for example, requiring forty hours within a two-year period). Id. The five outlier jurisdictions include Montana and South Dakota, which have no CME requirements, and Colorado, Indiana, and New York, which require only a small number of hours for specific topics such as pain management. Id.

88. In most jurisdictions, most required CME hours must be fulfilled with what are commonly referred to as "Category 1" credits. Id. As defined by the American Medical Association, "Category 1" credits broadly include activities sponsored by providers accredited by the Accreditation Council for Continuing Medical Education or otherwise recognized by the AMA as educationally "valid" and accredited by the AMA itself. See AM. MED. Ass'N \& ACCREDITATION COUNCIL FOR CONTINUING MED. Educ., ACCREDITATION COUNCIL FOR CONTINUING MEDICAL EDUCATION (ACCME) AND AMERICAN MEDICAL ASSOCIATION (AMA) GLOSSARY OF TERMS AND DEFINITIONS 3 (2017), https://www.ama-assn.org/sites/ama-assn.org/files/corp/mediabrowser/public/physicians/cme/ama-accme-glossary-terms.pdf [https://perma.cc/RFV9-XGXA] (defining “AMA PRA Category 1 Credit”); see also AM. MED. Ass'N, THE AMA's PHYSICIAN's RECOGNITION AWARD AND CREDIT SYSTEM 7-9 (2017), https://www.ama-assn.org/sites/amaassn.org/files/corp/media-browser/public/cme/pra-booklet_0.pdf [https://perma.cc/Z2ZG-YKGN].

89. Relying on the 2015 version of the FSMB Chart, Aparicio et al. observed that fifteen jurisdictions required a portion of required CME hours to be related to the doctor's area of specialty. Aparicio et al., supra note 81, at 10, 15 n.13. However, the 2021 version of the FSMB chart reflects that just six states have such a requirement: Arkansas, Connecticut, Nevada, North Carolina, South Carolina, and West Virginia. See FSMB Chart, supra note 86.

90. See FSMB Chart, supra note 86; see also Lawrence T. Sherman \& Kathy B. Chappell, Global Perspective on Continuing Professional Development, 3 ASIA PAC. SCHOLAR 1, 4 (2018) (describing the development of opioid strategy CME programs).

91. See, e.g., Jeffrey Hunt et al., Lifelong Learning for Professional Development in Psychiatry: Pedagogy, Innovations, and Maintenance of Certification, 42 PSYCHIATRIC CLINICS N. AM. 425, 429 (2019).

92. Am. BD. Med. Specialties, Standards for the ABMS Program For MAINTENANCE OF CERTIFICATION (MOC) 6-13 (Jan. 15, 2014), https://www.abms.org/wpcontent/uploads/2020/11/standards-for-the-abms-program-for-moc-final.pdf [https://perma.cc/886Y-JQFL] (describing the four MOC parts). 
not need to be board-certified to practice medicine, but board certification is increasingly required to obtain hospital staff privileges, participate in physician networks, and obtain reimbursement for services. ${ }^{93}$ Unlike lawyers-few of whom are certified specialists ${ }^{94}$ _eighty-two percent of physicians are boardcertified in their specialty areas and thus are required to take practice-specific CME. ${ }^{95}$

Within the MOC process, CME is specifically required for the "Lifelong Learning and Self-Assessment" segment, commonly referred to as "MOC Part II." 96 Particular requirements are left to the individual specialty boards, but the American Board of Medical Specialties, an umbrella organization, specifies that no fewer than twenty-five CME credits should be required annually. ${ }^{97}$ Easing the burdens of time and expense, CME courses taken to satisfy MOC requirements generally count toward jurisdictional MOL requirements as well. ${ }^{98}$

The MOC program builds in tools to guide physicians' CME choices. ${ }^{99}$ Recognizing that physicians' perceptions of their own learning needs may miss

93. E.g., Lewis R. First et al., Maintenance of Certification-A Prescription for Improved Child Health, 171 J. AM. MED. Ass'N PEDIATRICs 317, 318 (2017); Vandergrift et al., supra note 82 , at 1684 .

94. See supra note 21 and accompanying text.

95. The 2018 Census of Licensed Physicians by the Federation of State Medical Boards found that eighty-two percent of medical doctors and osteopaths, combined, were specialty-board certified. See Aaron Young et al., FSMB Census of Licensed Physicians in the United States, 2018, 105 J. MED. REGUL. 7, 11, 21 (2019). A 2005 article reported that more than eighty-five percent of medical doctors were board certified. Stephen H. Miller, American Board of Medical Specialties and Repositioning for Excellence in Lifelong Learning: Maintenance of Certification, $25 \mathrm{~J}$. Continuing Educ. Health PROS. 151, 153 (2005).

96. AM. BD. MED. SPECIALTIES, supra note 92, at 8; see also Hunt et al., supra note 91, at 431 (describing development of the four-part MOC system, including the CME-focused Part II); Eric S. Holmboe \& Christine Cassel, Continuing Medical Education and Maintenance of Certification: Essential Links, 11 PeRmanENTE J. 71, 72 (2007). The other parts include "Professional Standing and Professionalism" (Part I), "Assessment of Knowledge, Skills and Judgment" (Part III), and "Improvement in Medical Practice" (Part IV). AM. BD. MED. SPECIALTIES, supra note 92, at 2.

97. AM. BD. MED. SPECIALTIES, supra note 92 , at 8 .

98. See, e.g., HAw. CODE R. § 16-85-34(a)(2) (LexisNexis 2020); IOWA AdMIN. CodE r. 653-11.2(2) (2020); N.M. CODE R. § 16.10.4.10(C) (2020); 21 N.C. ADMIN. CODE 32R.0103(c) (2020); see also Jann Torrance Balmer, The Transformation of Continuing Medical Education (CME) in the United States, 4 ADVANCES MED. EDUC. \& PRAC. 171, 176 (2013) (noting FSMB recommendation that state medical boards count fulfillment of MOC requirements toward fulfillment of MOL requirements); Richard M. Burwick et al., Recent Trends in Continuing Medical Education Among Obstetrician-Gynecologists, 117 OBSTETRICS \& GYNECOLOGY 1060, 1061 (2011) (noting that CME required for the MOC process was sufficient to meet MOL requirements in most states).

99. See Tristan Gorrindo \& Saundra L. Stock, Bringing Education to the Bedside: A Primer on Continuing Medical Education (CME) and Maintenance of Certification (MOC) Requirements, 
the mark, the MOC process includes regular and extensive self- and peerassessment processes to identify particular deficiencies in the physician's practice. ${ }^{100}$ That data is then incorporated by the physician into a learning plan so that courses can be chosen for maximum impact. ${ }^{101}$

To be sure, many CME courses continue to fit the traditional lecture model and many scholars and attendees put this fact front and center of their criticism of the CME system. ${ }^{102}$ But, lectures can be part of a well-rounded CME agenda, "predispos[ing]" physicians toward the types of change that can be accomplished by non-lecture courses. ${ }^{103}$ And, non-lecture CME options abound.

The medical profession recognized decades ago the need to incorporate effective adult learning practices into CME, and CME providers have put those principles to work. ${ }^{104}$ Many CME courses now incorporate opportunities for multiple sessions, practice, feedback, small group discussion, and other features designed to impact medical practice in an enduring way. ${ }^{105}$ The list of innovations is long, including such diverse activities as simulations, ${ }^{106}$ reflection-based exercises, ${ }^{107}$ case-based self-assessments, ${ }^{108}$ reading

53 J. AM. ACAD. ChILD \& AdOLESCENT PsychiatRy 1042, 1042 (2014); Holmboe \& Cassel, supra note 96 , at $71-72$.

100. Gorrindo \& Stock, supra note 99, at 1042; Price, supra note 85, at 917; Jason Sheehan et al., Identification of Knowledge Gaps in Neurosurgery Using a Validated Self-Assessment Examination: Differences Between General and Spinal Neurosurgeons, 80 WORLD NEurosurgery e27, e28 (2013).

101. Gorrindo \& Stock, supra note 99, at 1042; see also Sheehan et al., supra note 100, at e28 (describing self-assessment tool as part of the MOC process for surgeons where the selfassessment itself earns CME credit).

102. See Curtis A. Olson \& Tricia R. Tooman, Didactic CME and Practice Change: Don't Throw That Baby Out Quite Yet, 17 Advances Health SCIS. EduC. 441, 442 (2012) ("The sharpest criticism [of CME] has been reserved for didactic CME."); see also Aparicio et al., supra note 81 , at 8 (identifying continuing CME "challenges," including "passive" CME courses; other criticisms included the "overly costly and onerous" nature of CME requirements).

103. See Paul E. Mazmanian \& David A. Davis, Continuing Medical Education and the Physician as a Learner: Guide to the Evidence, 288 J. AM. MED. Ass'N 1057, 1058 (2002); see also Gorrindo \& Stock, supra note 99, at 1042-43; Olson \& Tooman, supra note 102, at 442-43.

104. See, e.g., Aparicio et al., supra note 81, at 10 (describing the influence of adult learning principles on evolving CME structures); Sherman \& Chappell, supra note 90, at 1,3-4 (describing CME's evolution away from a single-session didactic lecture model).

105. See, e.g., Linda Casebeer et al., A Controlled Trial of the Effectiveness of Internet Continuing Medical Education, 6 BMC MED. 37, 38 (2008) (describing the growth of more varied online options); Vandergrift et al., supra note 82, at 1684 (describing the diversity of available activities and providers); Sherman \& Chappell, supra note 90, at 3-4 (describing the current system, which "encompass[es] a wide range of educational experiences").

106. See, e.g., Hunt et al., supra note 91, at 433.

107. See, e.g., id. at 434.

108. See, e.g., Glenda G. Callender et al., Maintenance of Certification: What Everyone Needs to Know, 224 ANNALS SurgicAl ONCOLOGY 1051, 1053 (2015). 
modules, ${ }^{109}$ and opportunities to learn alongside nurses, social workers, pharmacists, and other non-physician members of patient care teams. ${ }^{110}$ As discussed below, empiricists have put these CME innovations to the test.

\section{B. A Requirement Supported and Impacted by Decades of Research}

In a 2014 report, Ronald Cervero and Julie Gaines synthesized the state of CME research at that time. ${ }^{111}$ They found that since the 1960s, hundreds of individual empirical studies had tested the effectiveness of CME. ${ }^{112}$ Moreover, thirty-nine systematic reviews had assessed the quality and conclusions of those individual studies. ${ }^{113}$

Based on this body of evidence, particularly the most recent systematic reviews, Cervero and Gaines concluded that, overall, CME has a positive impact on the medical profession, particularly where the CME is more interactive, uses a variety of methods, involves multiple exposures for longer periods of time, and focuses on outcomes considered important by physicians. ${ }^{114}$ Though not expressly identified as such by Cervero and Gaines, these distinguishing features are key tenets of effective adult learning. ${ }^{115}$

In assessing CME efficacy, many CME scholars embrace a model developed by Donald L. Kirkpatrick, or a model similar to Kirkpatrick's. ${ }^{116}$ The Kirkpatrick model is part of the broader literature on designing and assessing professional training programs. ${ }^{117}$ Adapted for CME purposes, this model assesses potential impacts at four levels: (1) the extent to which the learner feels satisfied with the CME program; (2) the extent to which the learner gains and retains knowledge from the program; (3) the extent to which the learner's

109. See, e.g., id. at 1053.

110. See, e.g., Balmer, supra note 98, at 177-78.

111. Ronald M. Cervero \& Julie K. Gaines, Effectiveness of Continuing Medical Education: Updated Synthesis of Systematic Reviews, ACCREDITATION COUNCIL FOR CONTINUING Med. EDUC. (2014),

https://www.accme.org/sites/default/files/652_20141104_Effectiveness_of_Continuing_Medical_ Education_Cervero_and_Gaines.pdf [https://perma.cc/NEM2-KVBJ].

112. Id. at 3 .

113. Id. at 15 .

114. Id. at 3 .

115. See, e.g., Aparicio et al., supra note 81, at 14; Hunt et al., supra note 91, at 427.

116. See Claire A. Surr et al., Effective Dementia Education and Training for the Health and Social Care Workforce: A Systematic Review of the Literature, 87 REv. EDUC. RsCH. 966, 970 (2017) (explaining criticisms of and alternatives to the Kirkpatrick model but also noting that it "remains a widely applied approach to considering the levels at which it is helpful to evaluate training"); see also Jing Tian et al., A Systematic Review of Evaluation in Formal Continuing Medical Education, 27 J. ContinUing EdUC. HeAlth Pros. 16, 16 (2007); The Kirkpatrick Model, KIRKPATRICK PARTNERS, https://www.kirkpatrickpartners.com/Our-Philosophy/The-KirkpatrickModel (last visited Aug. 1, 2021) [https://perma.cc/N3S3-VA8D].

117. Surr, supra note 116, at 970; see also The Kirkpatrick Methodology - A Brief History, KIRKPATRICK PARTNERS, https://www.kirkpatrickpartners.com/Our-Philosophy/The-KirkpatrickModel [https://perma.cc/22RZ-Y2AL]. 
practice improves; and (4) the extent to which the learner's patients experience improved health outcomes. ${ }^{118}$ The model is hierarchical, with the first Kirkpatrick level being the easiest to measure, ${ }^{119}$ and the fourth being the hardest. ${ }^{120}$

Attendee satisfaction with a CME program is commonly assessed by means of post-course surveys, even in the absence of a planned empirical study. ${ }^{121}$ Indeed, many post-program assessments are limited to participant satisfaction, even when CME standards technically require a learning assessment. ${ }^{122}$ While such information reveals little about real-world impacts on physicians and patients, it can usefully indicate to CME planners how best to construct courses that will resonate with physician learners.

For example, John Ratelle et al. responded to a gap in the literature regarding hospitalists' satisfaction with hospital medicine CME programs. ${ }^{123}$ These researchers surveyed hospitalists who attended a four-day CME program comprised of thirty-two didactic hospital medicine presentations, some of which incorporated more interactive features such as polling and other audience response systems. ${ }^{124}$ The researchers found greater satisfaction with the courses that incorporated such features, a finding consistent with prior research results in other medical specialties. ${ }^{125}$

118. See, e.g., Hunt et al., supra note 91, at 434; Tian et al., supra note 116, at 16. Another commonly adopted model was developed by Professor Donald E. Moore. See Donald E. Moore, et al., Achieving Desired Results and Improved Outcomes: Integrating Planning and Assessment Throughout Learning Activities, 29 J. CONTINUING EdUC. HEALth PROS. 1 (2009). Moore's sevenlevel model is similar to Kirkpatrick's, but it assesses learner "participation" as well as "satisfaction," and it divides both "knowledge" and "health" impacts into two more granular assessment levels. Id. at 2-3.

119. See, e.g., Hunt et al., supra note 91, at 434 (noting that most studies reviewed by the authors went no further than the satisfaction and knowledge levels); Tian et al., supra note 116, at 20 (same).

120. See, e.g., Cervero \& Gaines, supra note 111, at 3 (finding that CME studies demonstrate the least "reliably positive impact" at the patient health outcomes level); P. Kristina Khanduja et al., The Role of Simulation in Continuing Medical Education for Acute Care Physicians: A Systematic Review, 43 CRITICAL CARE MED. 186, 191 (2015) (noting the "challenges inherent in conducting studies" at the highest Kirkpatrick level); S. Wallace \& S.A. May, Assessing and Enhancing Quality Through Outcomes-Based Continuing Professional Development (CPD): A Review of Current Practice, 179 VeterinaRY ReC. 515, 518 (2016) (noting that the literature regarding impacts at the clinical practice and patient health levels "is still in its infancy").

121. See, e.g., Sherman \& Chappell, supra note 90, at 3 (documenting the use of such surveys from at least the early 2000s).

122. See Michele Karnes et al., A Continuing Education Seminar for Health Professionals, 7 INT'L J. HEALTH, WELLNESS, \& SOC'Y 73, 73 (2017).

123. John T. Ratelle et al., Associations Between Teaching Effectiveness Scores and Characteristics of Presentations in Hospital Medicine Continuing Education, 10 J. HosP. MED. 569,569 (2015).

124. Id. at $570-71$

125. Id. at 572. Examples of other CME studies assessing learner satisfaction include: Burwick et al., supra note 98 (finding that obstetrician-gynecologists changed their CME choices 
Somewhat more difficult to measure is CME's impact on attendee knowledge, Kirkpatrick's second level. Testing before and after a CME program can measure immediate gains. More complicated and expensive is assessing attendees' retention of the new knowledge, requiring periodic followup through testing or self-reporting by participants. ${ }^{126}$

For example, in 2005, interest was high in the potential benefits of online CME, which, compared to live presentations, offered greater attendance flexibility and greater adaptability to individual learning styles. ${ }^{127}$ Noting the absence of rigorous empirical studies comparing live and online methods, ${ }^{128}$ Michael Fordis et al. conducted a randomized control trial in which ninetyseven primary care physicians were assigned to participate in either an online CME course that could be completed in multiple sessions over two weeks or a single live interactive workshop. ${ }^{129}$ Both sessions incorporated similar multifaceted instructional approaches to screening for and treating problematic cholesterol levels. ${ }^{130}$ Physician knowledge was assessed before and immediately after the course and then again twelve weeks later. ${ }^{131}$ Knowledge gains demonstrated on the post-course assessments were statistically significant and similar for the two randomized groups, leading the researchers to the important conclusion that online CME could produce knowledge benefits comparable to less-adaptable live presentations. ${ }^{132}$

to comply with new MOC requirements but that such choices did not reflect their CME preferences); James H. Jones et al., Lifelong Learning and Self-Assessment Is Relevant to Emergency Physicians, 45 J. EMERGENCY MED. 935 (2013) (finding that completing targeted readings as part of a CME activity for emergency physicians was well received by participants, who reported that the readings were relevant to and would help them change their clinical practices); and Christopher R. Stephenson, Flipping the Continuing Medical Education Classroom: Validating a Measure of Attendees' Perceptions, 36 J. Continuing Educ. Health Pros. 256 (2016) (finding that participants' perceptions of "flipped classroom" learning improved after participating in a flipped classroom CME course).

126. See, e.g., Karnes, supra note 122, at 73; David W. Price et al., Longitudinal Assessments in Continuing Specialty Certification and Lifelong Learning, 40 MED. TCHR. 917, 917 (2018).

127. Michael Fordis et al., Comparison of the Instructional Efficacy of Internet-Based CME With Live Interactive CME Workshops: A Randomized Control Trial, 294 J. AM. MED. Ass'N 1043, 1044 (2005).

128. Id.

129. Id. at $1044-46$.

130. Id. at 1046 .

131. Id. at 1048 .

132. Id. at 1049. Examples of other CME studies assessing gains in learner knowledge include: Casebeer et al., supra note 105 (finding that physicians participating in an internet-based CME program performed better on case vignette questions administered directly after the program than they did on vignette questions administered before the program, and that the effect was stronger for primary care doctors than for specialists); Emily A Edelman et al., Provider Engagement in Precision Oncology Education: An Exploratory Analysis of Online Continuing Medical Education Data, 16 PERSONALIZED MED. 199 (2019) (finding knowledge improvements for both less and more experienced oncologists after participating in interactive case-based educational modules regarding 
Clinical impacts begin to be measured at the third Kirkpatrick level, widely recognized as essential given high incidences of sub-optimal medical care. ${ }^{133}$ Even a CME attendee who retains knowledge for some time after a training or demonstrates a new skill in a simulated circumstance will not necessarily put that knowledge or skill to work in a clinical setting. ${ }^{134}$ The third Kirkpatrick level assesses CME impacts on clinical practice, using measures such as long-term self-reporting or clinical observation. Many studies in this category find only partial or small, though still statistically significant, improvements from CME.

For example, Debra Gist et al. investigated the impact of a multiple-phase CME program on dermatologists' treatment of patients with psoriasis. ${ }^{135}$ In the first phase of the study, participant physicians reviewed their own medical charts for at least ten of their psoriasis patients, then reflected on their clinical performance as benchmarked against their peers. ${ }^{136}$ In the second phase, participants reviewed on-point educational materials and developed a plan for improvement. ${ }^{137}$ Finally, participants reviewed the charts of patients they treated six to twelve months after the second phase, reporting treatment changes (or not) to the investigators. ${ }^{138}$ The study concluded that this CME program significantly improved certain clinical aspects of the dermatologists' practice, including counseling psoriasis patients on their increased risk of cardiovascular problems. ${ }^{139}$ However, the program did not impact other aspects, including asking patients about their smoking habits. ${ }^{140}$

tumor testing); and Vandergrift et al., supra note 82 (finding that requiring more CME credits was correlated with greater knowledge gains but that shortening the time to complete those credits was not).

133. See, e.g., Wallace \& May, supra note 120, at 518-19 ("In human healthcare, it is estimated that 30 per cent to 40 per cent of patients do not receive care that is informed by the best evidence, and that 20 per cent to 50 per cent receive inappropriate care.").

134. See, e.g., Alexander Gregor \& David Taylor, Morbidity and Mortality Conference: Its Purpose Reclaimed and Grounded in Theory, 28 TEACHING \& LEARNING MED. 439, 445 (2016) ("[P]hysicians often make clinical practice decisions that are incongruous with their clinical knowledge.”); see also Wallace \& May, supra note 120, at 517.

135. Debra L. Gist et al., Impact of a Performance Improvement CME Activity on the Care and Treatment of Patients with Psoriasis, 72 J. AM. ACAD. DeRMAtology 516 (2014).

136. Id. at 517 .

137. Id.

138. Id.

139. Id. at $517-18$

140. Id. Other examples of studies assessing CME's impact on clinical practice include: Fordis et al., supra note 127, at 1049-50 (finding that although knowledge gains were similar, an online course produced greater performance impacts than a similar live course); William McIvor et al., Simulation for Maintenance of Certification in Anesthesiology: The First Two Years, $32 \mathrm{~J}$. CONTINUING EDUC. HEALtH PROS. 236, 236 (2012) (finding self-reported practice improvements in anesthesiologists who completed a mannequin-based simulation CME program); and Sofia Valanci-Aroesty et al., Implementation and Effectiveness of Coaching for Surgeons in Practice - A Mixed Studies Systematic Review, 77 J. SURGICAL EdUC. 837, 837 (2020) (finding, in a systematic 
CME scholars recognize patient health impacts, the fourth Kirkpatrick level, as the "ultimate" CME goal. ${ }^{141}$ However, relatively few studies have attempted this measurement, many that do find mixed or no impact, and the quality of the evidence is relatively poor. ${ }^{142}$ A significant assessment problem is the possibility, even likelihood, that patient health may be impacted by many factors other than just the physician's CME training. ${ }^{143}$ Still, some scholars have chipped away at this elusive goal, and, overall, systematic reviews of the literature find support for the conclusion that well-designed CME can positively impact patient outcomes. ${ }^{144}$

For example, Brian Lee et al. investigated the impact of a CME program on the health of diabetic patients. ${ }^{145}$ The CME program was designed to address the problem of physicians failing to appropriately intensify therapy (such as by increasing medication) for diabetic patients with problematic glycemic control. ${ }^{146}$ Participants attended live lectures and then online case-based interactive sessions that were algorithmically tailored to each participant based on their responses to questions following the live event. ${ }^{147}$ Patient glycemic levels were found to improve, as documented in their medical charts. ${ }^{148}$ Reflecting the difficulty of this level of assessment, the researchers described the impact on patient outcomes as only "potentially" significant, given the possibility that factors not measured in the study contributed to better glycemic control and the possibility of bias in the subject physicians' choice of patients to include in the study. ${ }^{149}$

review, that coaching programs, unlike traditional CME, led to self-reported improvements in surgical practice).

141. See, e.g., Wendy Levinson et al., Developing Communication Skills for PatientCentered Care, 29 HeAlth AfFairs 1301, 1313 (2010).

142. See, e.g., SPYRIDON S. MARINOPOUlos ET AL., EFFECTIVENESS OF CONTINUING Medical Education 46 (2007); Paul E. Mazmanian et al., Continuing Medical Education Effect on Clinical Outcomes, 439 CHEST J. 49s, 51s (2009); Steven E. Nissen, Reforming the Continuing Medical Education System, 313 J. AM. MED. Ass'N 1813, 1813 (2015).

143. See, e.g., Khanduja et al., supra note 120, at 191; Manning \& DeBakey, supra note 81, at 19; Mazmanian et al., supra note 142, at 53s-54s.

144. See, e.g., Cervero \& GAINES, supra note 111, at 3; LOUISE Forsetlund ET AL., CONTINUING EDUCATION MEETINGS AND WORKSHOPS: EFFECTS ON PROFESSIONAL PRACTICE AND HeAlth CARE OutComes 12 (Cochrane Database of Systematic Reviews ed., 2009); Mazmanian et al., supra note 142 , at $53 \mathrm{~s}$.

145. See Brian Lee et al., Improving Type 2 Diabetes Patient Health Outcomes with Individualized Continuing Medical Education for Primary Care, 7 DiABETES THERAPY 473, 474, 477-78 (2016).

146. Id. at 474 .

147. Id.

148. Id. at 475-76. The researchers also found improvements in participant knowledge and practice. Id.

149. Id. at 477, 479-80. Examples of other CME studies assessing patient impacts include: V. Jane Derebery et al., Evaluation of the Impact of a Low Back Pain Educational Intervention on Physicians' Practice Patterns and Patients' Outcomes, 44 J. OCCuPATIONAL ENV'T MeD. 877, 877 (2002) (finding that patients of occupational medicine physicians missed less work after the 
As demonstrated by the foregoing examples, CME research has proceeded in iterative and incremental fashion. No overarching key to CME efficacy has been found, and the literature abounds with disagreement regarding CME's actual and potential impact for positive change. ${ }^{150}$ Certainly much work remains to be done, particularly at the higher Kirkpatrick levels of desired impact. CME has, however, made substantial strides, and the field's robust empirical work lays the groundwork for continuing improvements.

\section{PATIENT- AND CLIENT-CENTERED COMMUNICATION}

The dearth of CLE empirical study leaves a wide-open canvas for researchers. This section suggests a particular research focus: CLE's potential to impact lawyers' ability to communicate effectively with their clients using client-centered techniques. Researchers pursuing this line of inquiry would have a head start in two ways.

First, substantial work along these lines has already been accomplished in the comparable field of patient-centered communication for physicians. Medical empiricists have studied both effective physician communication skills and how those skills can be taught through CME. Underlying similarities between the communication needs and expectations of medical patients and those of legal clients make this well-established body of work a potential model for legal researchers. ${ }^{151}$

Second, legal empiricists have already started to dig into the underlying question of how lawyers can most effectively communicate with their clients, even if not nearly to the same extent as the subject has been studied in the medical realm. ${ }^{152}$ This existing research suggests that a client-centered style

physicians completed a multifaceted course on lower-back pain management that included consideration of their own practice statistics); Wayne A. Ray et al., Educational Programs for Physicians to Reduce Use of Non-Steroidal Anti-Inflammatory Drugs Among Community-Dwelling Elderly Persons: A Randomized Controlled Trial, 39 MED. CARE 425, 425 (2001) (finding that an educational program involving personal observation and placing reminders in patient charts reduced medication use by elderly patients to more desirable levels); and Ilene H. Zuckerman et al., Impact of an Educational Intervention for Secondary Prevention of Myocardial Infarction on Medicaid Drug Use and Cost, 10 AM. J. MANAGED CARE 493, 493 (2004) (finding a print-based CME program positively impacted patient adherence to prescribed medication regimens).

150. See, e.g., CERVERO \& GAINES, supra note 111, at 10-15. Cervero and Gaines observed that many in the medical community appeared to be unaware of the breadth and depth and overall favorable conclusions reached by empiricists, leading to a more negative public opinion than may be warranted. Id. at 15; see also Aparicio et al., supra note 81, at 14 (noting that lack of familiarity with CME research "has propagated doubt about its value").

151. See Cary Bricker, Teaching the Power of Empathy in Domestic and Transnational Experiential Public Defender Courses, 32 BUFF. PUB. INT. L.J. 1, 14-15 (2014); Gay Gellhorn, Law and Language: An Empirically-Based Model for the Opening Moments of Client Interviews, 4 CliniCal L. Rev. 321, 344 (1998).

152. See Bricker, supra note 151, at 15; Clark D. Cunningham, What Do Clients Want From Their Lawyers?, 2013 J. DISP. ReSOL. 143, 157 (2013); Marla Sandys \& Heather Pruss, Correlates 
may be significant to the client experience, to client outcomes, and to the incidence of complaints lodged by clients against their lawyers. Determining whether and how these communication skills can be taught through CLE would be a natural continuation of this important work.

\section{A. Patient-Centered Communication for Physicians}

As described by Wendy Levinson, a leader in the field, 153 "patientcentered" communication refers to verbal and non-verbal communication styles that 'increase health care providers' understanding of patients' individual needs, perspectives, and values; [] give patients the information they need to participate in their care; and [] build trust and understanding between physicians and patients." 154 The practice includes such elements as demonstrating empathy, asking questions that elicit honest and complete answers, explaining important medical details in a manner and at a pace that patients can understand, and creating a partnership where the physician and patient work together as a team. ${ }^{155}$

Medical empiricists have refined the profession's understanding of how and when "patient-centered" communication styles can be most effective and also how patient-centered communication skills can best be taught to continuing physician learners.

\section{Studying the Impact}

Substantial evidence demonstrates that patient-centered communication styles can improve important outcomes such as patient satisfaction, adherence to recommended treatments, and self-management of chronic disease. ${ }^{156} \mathrm{~A}$ meta-analysis of 127 individual studies, for example, found that patients of

of Satisfaction Among Clients of a Public Defender Agency, 14 OHIO State J. CRIM. L. 431, 435 (2017).

153. See Wendy Levinson, COMMONWEALTH FUND, https://www.commonwealthfund.org/person/wendy-levinson [https://perma.cc/CE2U-RDV8] (describing Levinson as an "international expert in the field of physician-patient communication.").

154. Levinson et al., supra note 141, at 1311; see also Rubén J. Nazario, Medical Humanities as Tools for the Teaching of Patient-Centered Care, 4 J. HosP. MED. 512,513 (2009).

155. See, e.g., Wendy Levinson et al., Physician-Patient Communication: The Relationship with Malpractice Claims Among Primary Care Physicians and Surgeons, 277 J. AM. MED. Ass'N 553, 553 (1997); Levinson et al., supra note 141, at 1310-11; Melissa Bekelja Wanzer et al., Perceptions of Health Care Providers' Communication: Relationships Between Patient-Centered Communication and Satisfaction, 16 HeAlth CoMmC'N 363, 365-66 (2004); Kelly B. Haskard Zolnierek \& M. Robin DiMatteo, Physician Communication and Patient Adherence to Treatment: A Meta-Analysis, 47 MED. CARE 826, 826 (2009).

156. Levinson et al., supra note 141, at 1311; see also Nazario, supra note 154, at 513; Beatrice Gabriela Ioan, The Role of Doctor-Patient Communication in Preventing Malpractice Complaints, 7 INT'L J. CommC'N RSCH. 303, 304 (2017); cf. Julia C. Prentice et al., Association of Open Communication and the Emotional and Behavioural Impact of Medical Error on Patients and Families: State-wide Cross-sectional Survey, 29 BMJ QUALITY \& SAFETY 883 (2020) (discussing evidence regarding negative impacts from a lack of patient-centered "open" communication). 
physicians who adopt a patient-centered communication style were nineteen percent more likely to adhere to their physician's medical advice. ${ }^{157}$

Many scholars in this area have pointed to the need for higher-quality research regarding impacts from patient-centered communication, particularly as regards impacts on patient health outcomes. ${ }^{158}$ Still, some researchers have demonstrated connections between patient-centered communication and positive clinical outcomes for particular health problems such as diabetes, hypertension, and cancer. ${ }^{159}$ In the cancer context, for example, a major review of the literature found patient-centered communication to be particularly important for health-related quality of life and survival "because of the levels of stress, uncertainty, complex information, and life-altering medical decisions that exist in such a setting." 160

Mixed results are not uncommon. For example, Julia Prentice et al. surveyed a large random sample of Massachusetts adults who perceived that they or a family member had been subjected to a medical error within the past six years. ${ }^{161}$ The study found that when physicians were frank about the error and invited meaningful dialogue, patients experienced less sadness and depression and felt less abandoned or betrayed; they also were less likely to avoid the particular doctor or healthcare institution involved. ${ }^{162}$ However, not all negative impacts were mitigated by patient-centered communication, including persistent anxiety and avoiding medical care generally. ${ }^{163}$ These mixed results led the researchers to call for additional research and evidencebased approaches to better understand and more comprehensively support patients harmed by medical error. ${ }^{164}$

157. Zolnierek \& DiMatteo, supra note 155 , at 832.

158. See, e.g., Ronald M. EPSTein \& Richard L. Street, Patient-Centered Communication in CANCer Care: Promoting Healing and Reducing SufFering 103 (Nat'l Cancer Inst. 2007) ("Longitudinal studies, mixed-method studies, and studies involving multiple sources of data are relatively uncommon but are needed to establish causal links between communication and outcomes."); Nicola Mead \& Peter Bower, Patient-Centered Consultations and Outcomes in Primary Care: A Review of the Literature, 48 PATIENT Educ. \& Counseling 51, 60 (2002).

159. Levinson et al., supra note 141, at 1311; see also Debra L. Roter et al., The Expression of Emotion Through Nonverbal Behavior in Medical Visits: Mechanisms and Outcomes, 21 J. GEN. INTERNAL MED. S28 (2006); Wanzer et al., supra note 155, at 364.

160. EPSTEIN \& STREET, supra note 158, at 99; see also Ioan, supra note 156, at 303-04 (describing patient-centered communication impacts on patient health, such as lowered blood pressure, increased adherence to medication regimes, and decreased duration of hospital stays); Prentice et al., supra note 156, at 890 (finding that honest communication about medical errors resulted in reduced emotional impacts on patients and reduced the incidence of patients avoiding future medical care).

161. Prentice et al., supra note 156 , at 884 .

162. Id. at $887-90$.

163. Id. at 892 .

164. Id. 
Even with the mixed results, the generally positive thrust of this research makes it perhaps unsurprising that a physician's patient-centered communication style has been linked to reduced malpractice claims against the physician. ${ }^{165}$ Indeed, a physician's communication style has been found to be a far better predictor of malpractice complaints than the quality of the physician's medical care. ${ }^{166}$

For example, Wendy Levinson et al. listened to audiotapes of patient visits with more than 120 physicians to discern which of the physicians employed more patient-centered communication techniques, such as encouraging patients to talk and soliciting their opinions. ${ }^{167}$ The researchers compared those observations to the record of claims against the physicians, concluding that patients who suffered bad health outcomes were less likely to sue primary care physicians with more caring and compassionate communication styles. ${ }^{168}$ Interestingly, this impact may not hold across all physician specialties; Levinson et al. found no relationship between communication style and complaints filed against surgeons. ${ }^{169}$ Levinson surmised, among other possible explanations, that patients might regard surgeons as technical experts from whom a more businesslike manner is expected. ${ }^{170}$

\section{Teaching the Skills Through CME}

A related body of empirical work establishes that effective patientcentered communication skills can be taught. All medical schools have incorporated communication skills into the curriculum. ${ }^{171} \mathrm{CME}$ has done the same, with measurable effects positively impacting doctors' communication

165. See, e.g., Richard C. Boothman et al., A Better Approach to Malpractice Claims? The University of Michigan Experience, 2 J. HEALTH \& LIFE SCIS. L. 125, 136 (2009); Nazario, supra note 154 , at 513 .

166. See, e.g., Levinson et al., supra note 141, at 1311 ('Patients' most frequent complaints are that physicians do not listen to their concerns, care about their problems, or provide enough information about their treatment.")

167. Levinson et al., supra note 155.

168. Id. at 558-59; see also Boothman et al., supra note 165, at 143 (finding malpractice claims fell after a health system implemented "open" communications practices); Bernard B. Virshup et al., Strategic Risk Management: Reducing Malpractice Claims Through More Effective Patient-Doctor Communication, 14 AM. J. MED. QUALITY 153, 154 (1999) (reviewing studies from the 1980s and 1990s establishing a correlation between patient-centered communication and fewer complaints).

169. Levinson et al., supra note 155 , at 558 .

170. Id.

171. Levinson et al., supra note 141, at 1312 (describing communication training in both the beginning and later phases of medical school); see also, e.g., Cynthia Haq et al., Integrating the Art and Science of Medical Practice: Innovations in Teaching Medical Communication Skills, 36 FAM. MED. S43 (2004) (describing curricular innovations in communication training at twelve medical schools); Evonne Kaplan-Liss et al., Teaching Medical Students to Communicate with Empathy and Clarity Using Improvisation, 93 ACAD. MED. 440 (2018) (reporting encouraging results of an improvisation-based course to build medical students' communication skills and empathy). 
styles and even patient health - that most elusive fourth level on the Kirkpatrick scale. ${ }^{172}$

Most of the empirical work assesses CME's impact on a physician's willingness and ability to employ more patient-centered communication methods. ${ }^{173}$ For example, L. Fallowfield et al. reviewed videotapes of oncologists meeting with their patients at three points in time: before an intensive three-day communication course, three months after the course, and again fifteen months after the course. ${ }^{174}$ The course incorporated numerous adult learning techniques, including simulation work in small groups led by experienced facilitators with oral feedback provided to participants in the moment and comprehensive written feedback provided later. ${ }^{175}$ Both the threemonth and fifteen-month assessments demonstrated significantly improved communication skills, including more effective ways of asking questions, responding to patient cues, and interrupting patients less often. ${ }^{176}$

Even short CME programs can improve patient-centered communication skills - an important finding given physicians' busy schedules. ${ }^{177}$ For example, Wei Wei Lee et al. studied both four-hour and ninety-minute programs designed to improve patient-centered communication in the common situation where a physician is looking at electronic health records while meeting with a patient. ${ }^{178}$ Previous studies had documented that physicians in this situation tend to focus more on the records than on the patient. ${ }^{179}$ Using both direct observation and post-course surveys, the researchers found that both versions of the course were effective, with attendees more likely to share their screens, demonstrate patient-

172. See, e.g., Gerald B. Hickson et al., Patient Complaints and Malpractice Risk, 287 J. AM. MED. Ass'N 2951, 2957 (2002); Levinson et al., supra note 155, at 559.

173. Levinson et al., supra note 141, at 1313.

174. L. Fallowfield et al., Enduring Impact of Communications Skills Training: Results of a 12-Month Follow-Up, 89 BRIT. J. CANCER 1445, 1445-46 (2003).

175. Id. at 1446. The course design aligned with what Levinson et al. described as key to the most effective communication programs: expert teachers, small group settings with individual feedback, and repetition to reinforce the lessons taught. See Levinson et al., supra note 141, at 131213 .

176. Fallowfield et al., supra note 174, at 1446-47. All measures of effective patientcentered communication remained steady or improved at the fifteen-month mark except for moments of empathy - a decline that the authors found troubling and requiring of further study. Id. at 1448; see also Barbara Maatouck-Bürmann et al., Improving Patient-Centered Communication: Results of a Randomized Control Trial, 99 PATIENT EduC. \& CounSELING 117, 118, 122 (2016) (finding significantly improved patient-centered communication skills after a three-day training program).

177. See Wei Wei Lee et al., Impact of a Brief Faculty Training to Improve Patient-Centered Communication While Using Electronic Health Records, 101 PATIENT EdUC. \& CounSELING 2156, 2157, 2160 (2018).

178. Id. at 2157 .

179. Id. at 2156 . 
centered body language, and use the electronic records to promote patient engagement in the conversation. ${ }^{180}$

The harder assessment is connecting CME communication training with impacts on patients, but, as Levinson has observed, the body of evidence in this regard is growing. ${ }^{11}$ For example, Debra Roter et al. studied the impact of an eight-hour communication course designed to help internists and family physicians address patients' emotional distress - a prevalent but often unrecognized problem arising from routine medical encounters. ${ }^{182}$ The researchers studied audiotapes of patient visits and telephone calls for up to six months after the course. Not only did the physicians demonstrate significantly more effective strategies for addressing patients' emotional well-being, but the patients themselves reported less emotional distress for the full six-month study period. ${ }^{183}$

Not all CME communication programs have the desired effect. For example, Patel et al. studied a CME program designed to improve patientcentered communication with Black and Latino/Hispanic children who suffered from asthma - populations with "remarkably high" urgent care use and death rates. ${ }^{184}$ Assessing outcomes at both nine and twenty-one months after the program, the researchers found that the participant physicians reported significantly greater confidence and use of patient-centered communication techniques. ${ }^{185}$ Not impacted, however, was the children's health, as measured by emergency room visits and other asthma-related outcomes. ${ }^{186}$ Reflecting on the lack of health impacts, the authors noted that the factors contributing to poor health outcomes are complex, suggesting that more than one-time and onemodality interventions may be necessary. ${ }^{187}$

180. Id. at 2159-60; see also Anna K. Donovan et al., Faculty Communication Knowledge, Attitudes, and Skills Around Chronic Non-Malignant Pain Improve with Online Training, 17 PAIN MED. 1985, 1986-87, 1989-90 (2016) (finding that a four-hour free online learning module improved physician communication knowledge, attitudes, and skills in managing patients with chronic non-malignant pain).

181. Levinson et al., supra note 141, at 1313.

182. Debra L. Roter et al., Improving Physicians' Interviewing Skills and Reducing Patients' Emotional Distress: A Randomized Clinical Trial, 155 ARCHIVES OF INTERNAL MED. 1877 (1995).

183. Id.; see also Adrienne Boissy et al., Communication Skills Training for Physicians Improves Patient Satisfaction, 31 J. GEN. INTERNAL MED. 755, 759-60 (2016) (finding that an eight-hour patient-centered communication course improved both patient and physician satisfaction); EPSTEIN \& STREET, supra note 158, at 174 (describing additional studies demonstrating that communication training for oncologists can have, but does not always have, a positive impact on the emotional well-being of patients and their quality of life); Zolnierek \& DiMatteo, supra note 155, at 832 (finding that training physicians in communication skills improved patient adherence to physician recommendations by twelve percent).

184. Minal R. Patel et al., Does Cross-Cultural Communication Training for Physicians Improve Pediatric Asthma outcomes? A Randomized Trial, 56 J. Asthma 273, 274 (2019).

185. Id. at $281-82$.

186. Id.

187. Id. at 283 . 
Much work remains to be done to test and re-test prior findings and to explore related areas. For example, use of remote health care increased dramatically during the COVID-19 pandemic and is expected to remain a dominant mode of health care delivery. ${ }^{188}$ How does patient-centered communication impact those interactions? ${ }^{189}$ As another example, malpractice premiums, proceedings, and payouts remain a drain on the healthcare system. ${ }^{190}$ Can CME programs impact communication styles in ways that measurably improve malpractice rates? ${ }^{191}$

The empirical path ahead in this area-both regarding the efficacy of patient-centered communication and the ability to teach it-will undoubtedly produce many mixed results and some CME programs will be proven to have little if any positive impact. Such results, however, are part of the empirical process, essential to understanding what does and does not work, and what might work better. ${ }^{192}$

\section{B. Client-Based Communication for Lawyers}

Similar to patient-centered communication for physicians, client-centered communication for lawyers generally refers to establishing a trusting relationship where information and advice are provided in a clear and empathetic manner. ${ }^{193}$ The lawyer in such a relationship encourages frank

188. See, e.g., Oleg Bestsennyy et al., Telehealth: A Quarter-trillion-dollar Post-COVID19 Reality?, MCKINSEY \& Co. (July 9, 2021), https://www.mckinsey.com/industries/healthcaresystems-and-services/our-insights/telehealth-a-quarter-trillion-dollar-post-covid-19-reality\#; Brian Gormley, Pandemic Could Spur Longer-Term Gains for Telemedicine, WALL ST. J. (Apr. 17, 2020), https://www.wsj.com/articles/pandemic-could-spur-longer-term-gains-for-telemedicine11587115802 .

189. See L. S. van Galen et al., Telehealth Requires Expansion of Physicians' Communication Competencies Training, 41 MED. TCHR. 714, 714-715 (2019) (detailing the dearth of empirical work on communication skills in the telehealth context).

190. See, e.g., Studies Highlight Continued Cost Burden of Medical Liability System, АM. HosP. Ass'N (Jan. 24, 2018), https://www.aha.org/news/headline/2018-01-24-studies-highlightcontinued-cost-burden-medical-liability-system; Marschall S. Runge, Here's How to Bring Down The Rate of Malpractice Claims, PITTSBURGH POST-GAZETTE (Mar. 24, 2019), https://www.postgazette.com/opinion/Op-Ed/2019/03/24/Here-s-how-to-bring-down-the-rate-of-malpracticeclaims/stories/201903240067.

191. See John Jolly et al., Evaluation of a Simulation-Based Risk Management and Communication Masterclass to Reduce the Risk of Complaints, Medicolegal and Dentolegal Claims, 6 BMJ SimUlATION \& TECH. ENHANCED LEARNing 69, 75 (2020) (noting the difficulty of empirically demonstrating a causal connection between CME communication courses and lowered rates of legal complaints).

192. E.g., EPSTEIN \& STREET, supra note 158, at 174-75.

193. See, e.g., David S. Dolowitz \& Jamila Abou-Bakr, Attorney-Client Relations in Divorce Cases: The Intersection of Ethics and Malpractice in Family Law, 31 J. AM. ACAD. MATRIM. L. 345, 356 (2019); Sara E. Gold, Trauma: What Lurks Beneath the Surface, 24 ClinICAL L. REV. 201, 217-18 (2018) 
discussion of all of the client's circumstances, resulting in a jointly developed strategy that accurately reflects the client's situation and goals. ${ }^{194}$

Legal empiricists have made some headway in studying the efficacy of client-centered communication styles. However, although many lawyer communication courses are offered for CLE credit, no headway has been made regarding CLE's ability to teach those skills. Given the potential for communication skills to impact the lawyer-client relationship, client outcomes, and complaints against lawyers, it is a path well worth exploring.

\section{Studying the Impact}

Survey research demonstrates that most clients perceive and appreciate lawyers practicing client-centered communication skills. Christopher Trudeau, for example, found a far more favorable response among members of the public, including those who had been represented by a lawyer, to written communications employing plain English than to written communications stuffed with legalese, Latin phrases, and other lawyer-centered legal writing choices. ${ }^{195}$ The latter made clients feel unintelligent and like the lawyer had abandoned the basic obligation of explaining complicated subject matter. ${ }^{196}$

Client-centered communication can also have a practical impact on client outcomes. For example, researchers from the RAND Corporation compared ten years of conviction and sentencing outcomes between two public defender offices. ${ }^{197}$ One of the offices adopted a substantially more "holistic" approach than the other. ${ }^{198}$ This approach included a client-centered communication plan that involved not only meaningful lawyer-client interviews, but also similarly geared conversations with and among other support professionals, such as drug and mental health counselors and health and immigration experts. ${ }^{199}$ This client-centered approach did not result in fewer convictions, but it did significantly improve the client's prospects of receiving no custodial sentence

194. See David A. Binder et AL., Lawyers as Counselors: A Client-Centered APPROACH 8-11 (2012) (identifying the "hallmarks" of client-centered conversations); Dolowitz \& Abou-Bakr, supra note 193, at 356; Gold, supra note 193, at 217-18, 225.

195. Christopher R. Trudeau, The Public Speaks: An Empirical Study of Legal Communication, 14 SCRIBES J. LEGAL WRITING 121, 140-41 (2012).

196. Id.; see also Christopher Campbell et al., Unnoticed, Untapped, and Underappreciated: Clients' Perceptions of Their Public Defenders, 33 BEHAV. SCIS. \& L. 751, 760 63 (2015) (finding that public defender clients were more satisfied with lawyers who incorporated client-centered communication techniques such as asking the client's opinion, listening closely, and keeping the client "informed of consequences"); Cunningham, supra note 152, at 143-44 (finding that seventy percent of large American law firms were dissatisfied with their outside counsel and that poor communication was a primary reason); Sandys \& Pruss, supra note 152, at 445, 450, 458 (finding that public defender clients were more satisfied with lawyers who used clear language, spent a good amount of time with the client, and listened to the client's story).

197. James M. Anderson et al., The Effects of Holistic Defense on Criminal Justice Outcomes, 132 HARV. L. REV. 819 (2019).

198. Id. at $822-23$.

199. Id. at $825,841-42$. 
or a shorter custodial sentence. ${ }^{200}$ The researchers attributed this result, in part, to the lawyers' better understanding of a client's circumstances, enabling them to communicate this information to the judge..$^{201}$

Lawyers do not necessarily practice what they preach when it comes to client-centered communication. British professor Daniel Newman both interviewed and observed lawyers in three legal aid offices. ${ }^{202}$ In interviews, the lawyers were quick to extol client-centered communication skills and to avow their own use of such skills. ${ }^{203}$ Observing the lawyers with their clients, however, told a different story, with the lawyers denigrating their clients' intelligence, assuming their guilt, and generally regarding their clients as "a different breed" of human being from themselves. ${ }^{204}$

Scholars have observed that failures in client communication are a significant cause of malpractice and disciplinary complaints filed against lawyers. ${ }^{205}$ Communication failures are particularly common in state bar disciplinary matters, as "prompt" and "reasonable" communication is required by every jurisdiction's rules of professional conduct. ${ }^{206}$ The literature in this regard generically describes the nature of the complaints as a "failure to communicate," but does not delve deeper into whether the problem is a complete failure to communicate important information or a failure to communicate in a client-centered manner ${ }^{207}$-yet another area ripe for exploration.

\section{Teaching the Skills Through CLE: A Research Agenda}

Researchers have used the results of empirical work regarding lawyers' communication styles to propose evidence-based models that would enable

200. Id. at 823 .

201. Id. at 879; see also Gellhorn, supra note 151, at 335 (finding that lawyers frequently interrupted or otherwise silenced clients at the very beginning of an initial client interview, when key information was often disclosed, with negative impacts on the resulting relationship and the interviewer's ability to tell the client's story in a legally and emotionally compelling manner).

202. Daniel Newman, Still Standing Accused: Addressing the Gap Between Work and Talk in Firms of Criminal Defence Lawyers, 19 INT'L J. LEGAL Pro. 3 (2012).

203. Id. at 4,8 .

204. Id. at $12-13,18$.

205. E.g., Nathalie Martin, The Virtue of Vulnerability, 48 Sw. U. L. REv. 367, 376-77 (2019) ("Failing to properly communicate with clients will not only land a lawyer in malpractice trouble, but also may lead to a disciplinary board complaint against the attorney."); Melissa Mortazavi, A No-Fault Remedy for Legal Malpractice?, 44 HOFSTRA L. ReV. 471, 480 (2015) ("Wrongs arising from failures in client communication continue to make up a sizeable portion of malpractice claims.").

206. See, e.g., Model Rules of Pro. CONDuCt r. 1.4(a) (AM. BAR Ass'N 2020) (detailing the particulars of a lawyer's obligation to communicate with clients).

207. See, e.g., Anita Bernstein, What Clients Want, What Lawyers Need, 52 EMORY L.J. $1053,1056 \&$ n.10 (2003) (reporting results of a review of bar association annual reports); Jennifer Gerarda Brown \& Liana G.T. Wolf, The Paradox and Promise of Restorative Attorney Discipline, 12 NEv. L.J. 253, 259-60 (2012) (describing disciplinary data from several jurisdictions). 
lawyers to communicate more effectively with their clients. ${ }^{208}$ Indeed, CLE courses on client communication abound. ${ }^{209}$ Missing, however, are empirical studies exploring how desired communication skills can best be taught in a CLE format and whether such teaching can result in real-world impacts to client experiences, client outcomes, and complaints against lawyers.

The two existing studies regarding client complaints and CLE, discussed in Part IIB, supra, underscore how more nuanced and rigorous study could advance the field. Both studies looked at the broad question of whether mandatory CLE reduced the number of complaints, or at least the number of well-founded and successful complaints, filed against lawyers. The answer was no. ${ }^{210}$ Taking a page from the CME literature, however, legal empiricists might discover useful information from a more granular and incremental research agenda focused on the potential of a particular type of CLE-client-based communication training - to impact client relations and outcomes.

As with all continuing education research, legal empiricists studying client communication courses might consider the four Kirkpatrick levels of impact. ${ }^{211}$ Looking to the first level, work could begin with understanding the type or types of CLE that are most satisfying for lawyers, thus laying the groundwork for appealing course designs aimed at higher-level impacts.

Beginning at this basic level would help to ensure a large number of willing subjects, thus avoiding a potential problem as lawyers have not generally been eager to turn the empirical spotlight on themselves. ${ }^{212}$ Many CLE courses already end with attendee satisfaction surveys, and CLE attendees are used to filling them out. ${ }^{213}$ The time commitment required to provide such feedback is minimal, and the information could be meaningful if the survey were designed by empirical research experts.

208. See, e.g., Bricker, supra note 151, at 20 (suggesting methods of teaching empathetic communications skills); Gellhorn, supra note 151, at 345 (proposing a model for conducting client interviews).

209. A google search for CLE courses on client communication brings up a wealth of offerings. For example, the American Bar Association offers a $\$ 195$ "Effective Client Communications" CLE course that promises, in sixty minutes, to teach lawyers to "adjust[] what [they] say and how [they] say it" in order to "improve the success" of their communications with current and prospective clients. Effective Client Communications - Increasing Your Impact by Avoiding the Mistakes That Lead to Dissatisfaction (On-Demand CLE), AM. BAR ASS'N, https://www.americanbar.org/events-cle/ecd/ondemand/353904546/.

210. Authors Ziegler and Kuhn might dispute this conclusion. See supra notes 62-69 and accompanying text.

211. See supra notes $116-120$ and accompanying text.

212. See Susan Saab Fortney, Taking Empirical Research Seriously, 22 GEO. J. LEGAL EтHICs 1473, 1477-80 (2009); David B. Wilkins, The Professional Responsibility of Professional Schools to Study and Teach About the Profession, 49 J. LegAL EDUC. 76, 91-92 (1999).

213. See, e.g., Fisher, supra note 45, at 173-74 (finding that ninety-two percent of the Kansas CLE providers participating in Fisher's study captured CLE attendee reactions through postcourse evaluations). 
A second-level study would assess immediate and long-term improvements in the lawyer's knowledge of client-centered communication skills. Such studies would likely be more invasive and time-consuming for the subject lawyers. To increase willingness, researchers venturing into this territory could explain the practical implications of the work-rethinking and reshaping CLE courses and requirements - to the participating lawyers. ${ }^{214}$

Researchers could also provide more concrete enticements. For example, physician participants in CME studies may earn extra CME credit for their participation, may have CME course fees waived, and, if the study involves observation, may be offered personal feedback on their mastery of the information or skill being taught. ${ }^{215}$ Such enticements should be attractive to lawyers as well.

Ultimately, like their CME counterparts, CLE researchers would aim for the third and fourth Kirkpatrick levels, studying real-world impacts from various CLE models: whether and how CLE trainings might improve lawyers' actual communication with clients and whether those changes can be measured in improved client outcomes or reduced numbers of complaints filed against lawyers.

To the extent such studies would involve collecting data about the practice of particular lawyers, confidentiality would likely be a significant concern. For example, the information collected might cast the lawyer or the lawyer's office in an unflattering light. ${ }^{216} \mathrm{CME}$ researchers have developed protocols to protect participant anonymity, including assigning unique identifiers in lieu of physicians' names. ${ }^{217}$ CLE researchers could similarly anonymize all references to individual lawyers and offices to avoid any potential for unwelcome publicity and disclosures. For example, Anna Offit's study of decision-making in a particular United States Attorney's Office took anonymizing precautions that included assigning a randomly generated code to each lawyer interviewed, modifying easily identified features of cases handled by the office, and describing the office generically rather than identifying it specifically. ${ }^{218}$

The most significant concern would be to protect sensitive client information. CME researchers have taken anonymizing measures to protect the

214. See Fortney, supra note 212, at 1480 ("Lawyers who understand the practical application of empirical findings should be more willing to personally participate in empirical studies and to encourage others to do so.").

215. See, e.g., Fallowfield et al., supra note 174, at 1446; Michael D. Hagen et al., Maintenance of Certification for Family Physicians (MC-FP) Self-Assessment Modules (SAMs): The First Year, 19 J. AM. BD. FAM. MED. 398, 399 (2006); Jones et al., supra note 125, at 936-37; Levinson et al., supra note 155, at 554; cf. MARINOPOUlOS ET AL., supra note 142, at 8 (finding that CME literature did not reveal whether inducements for participation, such as CME credit and financial rewards, impacted CME effectiveness).

216. See Fortney, supra note 212, at 1477-78.

217. See, e.g., Levinson et al., supra note 155, at 554; Roter et al., supra note 182, at 1878.

218. Anna Offit, Prosecuting in the Shadow of the Jury, 113 Nw. U. L. REV. 1071, 1084 85,1088 (2019) 
confidentiality of patients' medical information. ${ }^{219}$ However, confidentiality concerns regarding legal clients' information may be rather more acute given the possibility that researcher access might waive attorney-client privilege and might open the lawyer to professional discipline. ${ }^{220}$ The problem is significant enough that David Wilkins suggested in 1999 that legal empiricists should consider exploring areas that avoid client confidentiality concerns, such as lawyer career paths and compensation. ${ }^{221}$ As time has gone on, however, legal empiricists have developed methods of anonymizing client information sufficiently to account for potential problems arising from disclosure, at least to the satisfaction of the Institutional Review Boards that must approve research on live human subjects. ${ }^{222}$

\section{A CAUTIONARY NOTE: PRESSURE TO PRODUCE POSITIVE RESULTS}

Whatever aspects of CLE legal empiricists choose to study, they will need to be mindful of potential pressures from journals and institutions to prioritize results that are favorable to maintaining a mandatory CLE system.

First, scholarly journals, including law journals, that publish empirical work tend to favor studies demonstrating a positive effect from the hypothesis or intervention being tested and tend to disfavor studies with negative or inconclusive results. This "publication bias" incentivizes researchers to selectively report data and skews the body of published evidence away from documenting the absence of an impact. ${ }^{223}$ Accordingly, studies finding that

219. See, e.g., Levinson et al., supra note 155, at 554; Roter et al., supra note 182, at 1878 .

220. The obligation to protect client information is imposed on lawyers both by the attorneyclient evidentiary privilege and by rules of professional conduct. E.g., MODEL RULES OF PRO. CONDUCT r. 1.6 cmt. [3] (AM. BAR Ass'N 2020).

221. Wilkins, supra note 212, at 91.

222. See, e.g., Fortney, supra note 212, at 1480 (noting that the IRB process includes safeguards regarding confidentiality and anonymity); see also Bernstein, supra note 31, at 147 (discussing protocols for handling confidential information anonymously); Diamond, supra note 10, at 1233-35 (discussing the situation of legal empirical researchers who must promise confidentiality as a condition for access); Trudeau, supra note 195, at 129 (promising anonymity to participants agreeing to complete a questionnaire regarding their experiences with lawyer communications); Lisa Webley, Qualitative Approaches to Empirical Legal Research, in THE OXFORD HANDBOOK OF EMPIRICAL LEGAL RESEARCH 926, 936-37 (discussing client consent to tape interviews).

223. E.g., Annie Franco et al., Publication Bias in the Social Sciences: Unlocking the File Drawer, 345 ScI. 1502, 1504 (2014); Donald P. Green \& Dane R. Thorley, Field Experimentation and the Study of Law and Policy, 10 ANN. REV. L. \& SoC. SCI. 53, 67 (2014); Max M. Schanzenbach \& Robert H. Sitkoff, Reconciling Fiduciary Duty and Social Conscience: The Law and Economics of ESG Investing by a Trustee, 72 STAN. L. REV. 381, 443 n.340 (2020); David Alan Sklansky, Evidentiary Instructions and the Jury as Other, 65 STAN. L. REV. 407, 435-36 (2013). Relatedly, researchers sometimes do not even bother to write up the results of studies that find no positive results, a type of publication bias commonly referred to as the "file drawer" problem. E.g., Franco et al., supra, at 1502, 1504. 
CLE has little or no impact on lawyer knowledge or practice or on the client experience may face significant hurdles to publication.

Publication bias has been widely documented in medical empirical studies, ${ }^{224}$ and has been specifically noted in the context of experiments regarding CME efficacy. ${ }^{225}$ Some observers consider the problem to be even more pronounced in the social sciences and law. ${ }^{226}$ Indeed, legal scholars may be particularly apt to ignore publication bias pitfalls and accept published results uncritically. ${ }^{227}$

Although compliance is not universal, many biomedical journals take measures to combat the problem. For example, some leading journals now require researchers to adhere to rigorous transparency requirements, which help prevent selective reporting and misleading results. ${ }^{228}$ Perhaps the most significant bulwark against publication bias is the growing trend among scientific journals toward a "pre-registration" or "registered report" format where researchers submit a study protocol before the study begins; if the protocol passes peer review, the journal commits to publication regardless of the results, assuming that the researchers follow the protocol. ${ }^{229}$ Legal journals and researchers should adopt similar measures, and pressure is mounting in this regard. ${ }^{230}$ However, although some law journals have adopted guidelines requiring greater transparency of underlying data, most have not taken even this initial step. ${ }^{231}$

Second, conflicts of interest may tilt CLE research toward favorable findings. These conflicts would arise from the vested interests of the law schools, bar associations, and trade groups necessary to support legal empiricists undertaking a vigorous inquiry into the CLE system.

Legal empiricists are mostly law professors employed by law schools, doing research with resources, including paid leaves, provided by law schools. $^{232}$ Bar associations are major funders of research on the legal

224. E.g., Mohammed Hassan Murad et al., The Effect of Publication Bias Magnitude and Direction on the Certainty in Evidence, 23 BMJ EVIDENCE-BASED MED. 84, 84 (2018).

225. See ForSETLUND ET AL., supra note 144, at 12; MARINOPOULOS ET AL., supra note 142, at 7; Tian et al., supra note 116, at 21.

226. Sklansky, supra note 223 , at 436 .

227. Id.

228. Green \& Thorley, supra note 223 , at 67.

229. See, e.g., Jason Chin et al., Improving the Credibility of Empirical Legal Research: Practical Suggestions for Researchers, Journals, and Law Schools 10-12 (Boston U. Sch. of Law, Public Law \& Legal Theory Working Paper No. 20-32, 2020); Matthew Warren, First Analysis of 'Pre-Registered' Studies Shows Sharp Rise in Null Findings, NATURE (Oct. 24, 2018), https://www.nature.com/articles/d41586-018-07118-1.

230. See, e.g., Chin et al., supra note 229, at 4-5; Green \& Thorley, supra note 223, at 67.

231. See Chin et al., supra note 229 , at 17-18.

232. See generally LoPucki, supra note 42 (studying differences between legal empiricists with a J.D. degree only and those with Ph.D. degrees as well, all of whom are law professors). The rising number of law professors with Ph.D. degrees are less likely than their J.D.-only counterparts 
profession and also collect and hold substantial quantities of data on the legal profession. ${ }^{233}$ Industry organizations such as the Association for Continuing Legal Education ("ACLEA"), representing CLE trainers and managers, and CLEreg, representing mandatory CLE administrators, would similarly be important sources of data for CLE researchers. ${ }^{234}$

All of these institutions benefit from the mandatory CLE status quo. ${ }^{235}$ Most obviously, ACLEA and CLEreg would not exist without the system. Moreover, although figures regarding CLE profits to bar associations and law schools are not collected in any publicly available way, all state bar associations and the American Bar Association offer CLE courses for a fee, as do most American law schools. ${ }^{236}$

Of course, similar interests exist in the realm of CME research. However, the history of CME and the culture that has grown up around it has been one of vigorous scientific inquiry from the beginning, supported by academic, licensing, and other major professional organizations, including the American Medical Association. ${ }^{237}$

CLE has no such history or culture. Law schools, bar associations, and trade groups have done little more than pay occasional lip service to the need

to study the legal profession. See Lynn M. LoPucki, Disciplining Legal Scholarship, 90 TUL. L. REV. 1, 16-20 (2015).

233. See, e.g., Legal Profession Statistics, AM. BAR Ass'N, https://www.americanbar.org/about_the_aba/profession_statistics/(last visited Jan. 15, 2022); MD. ST. BAR ASS'N, TRENDS IN THE LEgAL PROFESSION (2020), https://issuu.com/marylandstatebarassociation/docs/summer_2020_trends_in_the_legal_professio n_report; OHIO St. BAR AsS'N, 2019 PROFILE OF THE LEGAL PROFESSION IN OHIO (2020), https://www.ohiobar.org/globalassets/public-resources/profile-of-legal-profession/pdfs/polppublic-may2020.pdf.

234. See ASS'N FOR CONTINUING LEgAL EDUC.,
https://associations.uslegal.com/association-for-continuing-legal-education/ (last visited Aug. 1, 2021) (describing ACLEA as "the best source for CLE information today"); CONTINUING LEGAL EDUC. REGULS. ASs'N, Reports and Papers, https://www.clereg.org/reports-and-papers (last visited Aug. 1, 2021) (listing reports and papers on the industry made available by CLEreg).

235. Sirota, supra note 9 , at 556.

236. Research notes on file with the author.

237. See, e.g., Balmer, supra note 98, at 173 (describing the involvement of many organizations in the development of evidence-based changes to the CME system). In the CME context, conflicts of interest most commonly arise from CME course sponsorship by medical device or drug companies with an interest in promoting their own products. See, e.g., Barbara Barnes, Financial Conflicts of Interest in Continuing Medical Education: Implications and Accountability, 317 J. AM. MED. Ass'N 1741, 1741-42 (2017). Such product-based conflicts are less significant for CLE. For example, even if LEXIS-sponsored CLE programs promoted the advantages of the LEXIS research platform, the potential harm to clients does not approach the significance of, say, an opioid manufacturer sponsoring CME programs on pain management. See, e.g., Alicia Ault, Lawsuits, Congressional Inquiry Plague Opioid Manufacturers, MEDSCAPE (March 30, 2017), https://www.medscape.com/viewarticle/877949\#vp_1 (describing a Congressional inquiry into whether opioid manufacturers' business practices, including CME sponsorship, "contributed to overprescribing and overuse of the drugs"). 
for critical inquiry. In 1987, for example, the American Bar Association convened what is commonly known as the "Arden III" conference to reflect on the state of CLE at that time; the participants agreed that the ABA should organize a study to determine whether mandatory CLE "enhanced competence." 238 Two decades later, the ABA and ACLEA convened a "Critical Issues Summit" for CLE professionals, law school deans and faculty, and other professional leaders. ${ }^{239}$ Participants" "Final Recommendations" recognized the need for CLE programs to "evolve" based on learning practices research. ${ }^{240}$ Virtually no CLE-focused research emerged from either initiative, and the mandatory system marches on. ${ }^{241}$

At least in the short term, empirical research casting doubt on the efficacy of CLE would redound poorly to the bottom lines of these organizations, requiring an expensive overhaul of the system and a reasoned response to calls for its elimination. Hopefully, these organizations will take up the challenge and support the work and results of empirical research, wherever they may lead.

\section{CONCLUSION}

More than forty-five years after the first states adopted mandatory CLE, the profession still has put forward no evidence to suggest that the system has any positive impact on the quality of American lawyering. One principled response to this circumstance would be to end the system, allowing lawyers to use the time and money saved as they see fit.

Another principled response would be to take up the empirical challenge. CLE courses are stuck in a lecture-based mode that we know from research in other fields is antithetical to effective adult learning, at least on its own. What different methods might work better to achieve real-world impacts on lawyers and their clients?

Lessons learned from CME research suggest that answers are out there. The potential for CLE to teach client-centered communication skills presents a particularly promising research agenda. This research would build on similar work in the medical arena and also on the work that legal empiricists already have begun regarding effective communication styles for lawyers. ${ }^{242}$

Challenges facing the field include potential pressures to de-emphasize findings critical of the mandatory CLE status quo. These challenges, however,

\footnotetext{
238. Rhode \& Ricca, supra note 3 , at 6.

239. AM. L. INST., AM. BAR Ass'N, \& ASS'N FOR CONTINUING LEgAL EDUC., CRITICAL ISSUES SUMMIT, FinAL RECOMMENDATIONS 1 (2009), https://www.clereg.org/assets/pdf/Critical_Issues_Summit-Final_Recommendations.pdf.

240. Id. at 5 .

241. See Rhode \& Ricca, supra note 3, at 6 ("[T] $]$ he absence of evidence concerning the effectiveness of mandatory CLE [has done] little to prevent its adoption.").

242. Ironically, a good way to share the results of such research may be through CLE courses themselves. See Fortney, supra note 212, at 1481 ("For my last national study, I found CLE programs to be a very worthwhile avenue for sharing results with practitioners.").
} 
cannot be allowed to derail the science. Either study and reform the system or end it. 